\title{
Alcohol drinking and cardiac risk
}

\author{
Benjamin Buemann*, Jørn Dyerberg and Arne Astrup \\ Research Department of Human Nutrition and Center for Advanced Food Studies, The Royal \\ Veterinary and Agricultural University, Rolighedsvej 30, 1958 Frederiksberg, Denmark
}

The present paper provides a comprehensive review of the literature pertaining to the impact of alcohol intake on cardiovascular disease. Both cross-sectional and prospective studies have disclosed a negative association between moderate intake of alcoholic beverages and cardiovascular disease. The relationship appears to be present for both wine, beer and spirits. Effects of alcohol itself and also the role of different cardioprotective substances in alcoholic beverages are discussed. Alcohol has been suggested to beneficially affect the blood lipid profile, as it increases plasma HDL-cholesterol level. Furthermore, it may inhibit thrombogenesis by reducing thromboxan formation and decreasing the plasma level of fibrinogen. However, high blood concentrations of alcohol may impair fibrinolysis by increasing plasma plasminogen activator inhibitor-1 level. This action could contribute to explaining the ' $U$ '-shaped association between alcohol intake and cardiac events. Alcohol seems to promote abdominal fat distribution, but the importance of this effect in non-obese individuals is uncertain. Wine in particular, but also beer, contains polyphenols which act as antioxidants. Their action could maintain the integrity of the endothelial function by reducing the formation of superoxide. Moreover, these antioxidants may protect against LDL oxidation and modulate the macrophage attack on the endothelium. Although the cardio-protective effect of alcohol can hardly be addressed in healthy individuals by intervention studies with hard end points, there are many observational and experimental findings indicating that moderate alcohol drinking possesses properties preventive of cardiovascular disease.

\section{Alcohol: Antioxidants: Blood lipids: Cardiovascular disease: Haemostasis: Alcoholic beverage}

\section{Introduction}

As an organic solvent it is obvious that ethyl alcohol has potent biological effects, and man has been delighted and seduced by the mental effects it causes. Since ancient times, when the

\footnotetext{
Abbreviations: CETP, cholesteryl ester transfer protein; LPL, lipoprotein lipase; MI, myocardial infarction; NIDDM, non-insulin-dependent diabetes mellitus; NOS, NO synthase; PAI-1, plasminogen activator inhibitor-1; t-PA, tissue-type plasminogen activator.

*Corresponding author: Benjamin Buemann, fax +45 352824 83, email BBU@KVL.DK
} 
euphoric effect of fermented berries was discovered, alcohol has caused many physical and mental problems in individuals with poor resistance. The consequences of abusive alcohol behaviour are numerous and include social derangement, infertility, fetal damage, malnutrition, liver cirrhosis, pancreatitis, intestinal problems, cancer, hypertension and cardiovascular diseases. Several of these conditions are probably related to the metabolic derangement caused by alcohol. When alcohol is oxidised in the liver $\mathrm{NAD}^{+}$is reduced to $\mathrm{NADH}$, and this process leads to a derangement of the redox potential in the liver cells, which affects a large number of other metabolic pathways (Lieber, 1991). One of the prominent results of altered redox status is the increased synthesis and trapping of fatty acids in triacylglycerols (Mezey, 1985). This process has an acute hypertriacylglycerolaemic effect, and may lead to hepatic steatosis in chronic excessive alcohol use.

Alcohol takes the highest position in the so-called oxidative hierarchy, and therefore replaces other energy-providing substrates while it is being metabolised (Prentice, 1995). Most of the acetate produced by alcohol oxidation in the liver enters the blood plasma to be taken up peripherally, where it is used as an oxidative substrate. As acetate is readily oxidised in the citric acid cycle (Skutches et al. 1979) it has a high substrate priority, and alcohol may therefore cause acute insulin resistance (Shah, 1988). These different adverse effects tend to imply that alcohol consumption must increase mortality at any level. However, epidemiological findings suggest otherwise. In prospective studies relating self-reported alcohol intake to all-cause mortality a ' $\mathrm{U}$ '- or ' $\mathrm{J}$ '-shaped curve is typically found, independently of other mortality risk factors such as smoking and obesity (Fig. 1; Grønbæk et al. 1994). How does the descending 'leg' of

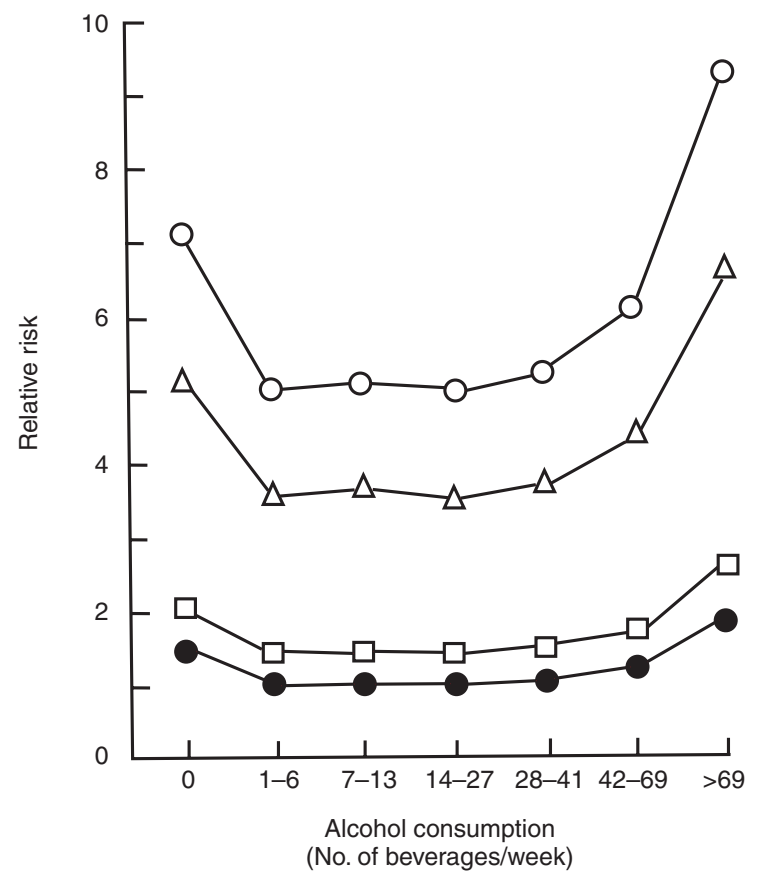

Fig. 1. Relative risk of mortality in relation to alcohol intake in smoking ( $>20 \mathrm{~g}$ tobacco/d; $\bigcirc-\circ, \triangle-\triangle)$ and non-smoking ( $\square-\square, \bullet-\bullet$ ), obese (BMI $>32.5 \mathrm{~kg} / \mathrm{m}^{2} ; \circ-\circ, \square-\square$ ) and lean (BMI $20-25 \mathrm{~kg} / \mathrm{m}^{2} ; \triangle-\triangle, \bullet-\bullet$ ) subjects. (Grønbæk et al. 1994; reprinted with permission from the BMJ Publishing Group.) 
this curve come about? Does alcohol possibly protect against one of the major killers in Western societies?

\section{What can epidemiology tell us about moderate drinking and cardiovascular diseases?}

\section{Population surveys}

That intake of wine may exert a protective effect against CHD was implied by the so-called French paradox. The French have a strikingly low incidence of CHD compared with that observed in other developed countries, despite a relatively high consumption of saturated fat in the form of dairy fat. However, when the potential effect of their high intake of wine is accounted for their mortality rate from CHD is equal to that found in other nationalities with a similar intake of dairy fats (Fig. 2; Renaud \& De Lorgeril, 1992). The outcome of this manipulation of statistical data does not prove that it is the high wine intake that protects the French against CHD. Other protective lifestyle factors, such as their intake of unsaturated fat and fruit and vegetables, may play a role, and the French mentality, with a relaxed way of living, has also been suggested to prevent the development of CHD (Cleophas, 1999).

If wine does protect against CHD what are then the mechanisms? The alcohol in wine is an obvious component to study. If alcohol, per se, has a cardio-protective effect, the negative association observed between wine consumption and CHD incidence should also be expected to be present when related to total alcohol consumption and individually to other types of alcoholic beverages. In ecological studies the incidence rate of CHD in different countries is studied in relation to the corresponding national records of alcohol consumption. In this type of study a negative correlation between total per capita alcohol consumption and deaths from atherosclerotic heart disease has been found. Nevertheless, beer consumption was reported to be positively related to atherosclerotic heart death (LaPorte et al. 1980), an observation also found in a later study (Nanji, 1985). However, beer consumption was also strongly correlated with the consumption of meat which was also related to the cardiac death rate. The interpretation of such observations is therefore very difficult. In general, a variety of factors which may differ between countries, such as dietary habits, physical activity, smoking and health care, could confound such ecological data. More recent ecological studies have adjusted for some potential confounding factors like smoking, the composition of consumed fat, or the intake of fruit and vegetables. These studies show a negative association between CHD death rate and wine intake, unlike that for beer or spirits consumption (Rimm et al. 1996). However many important confounding factors may still be unaccounted for and, furthermore, the total consumption rate of a particular type of beverage in any given country does not provide any information about how consumption is distributed amongst its population. Similar consumption rates for alcohol in wine and spirits in a society could reflect a moderate intake of wine in the majority of the population but an excessive intake of spirits in a minor subpopulation, with a consequent detrimental rather than beneficial impact on the heart (Cleophas, 1999).

\section{Case-control and prospective cohort studies}

Such studies relating alcohol intake to CHD events between specific individuals may be more conclusive, although they may still be confounded by inter-individual variations in other lifestyle factors. However, due to the large number of observations in such studies more 

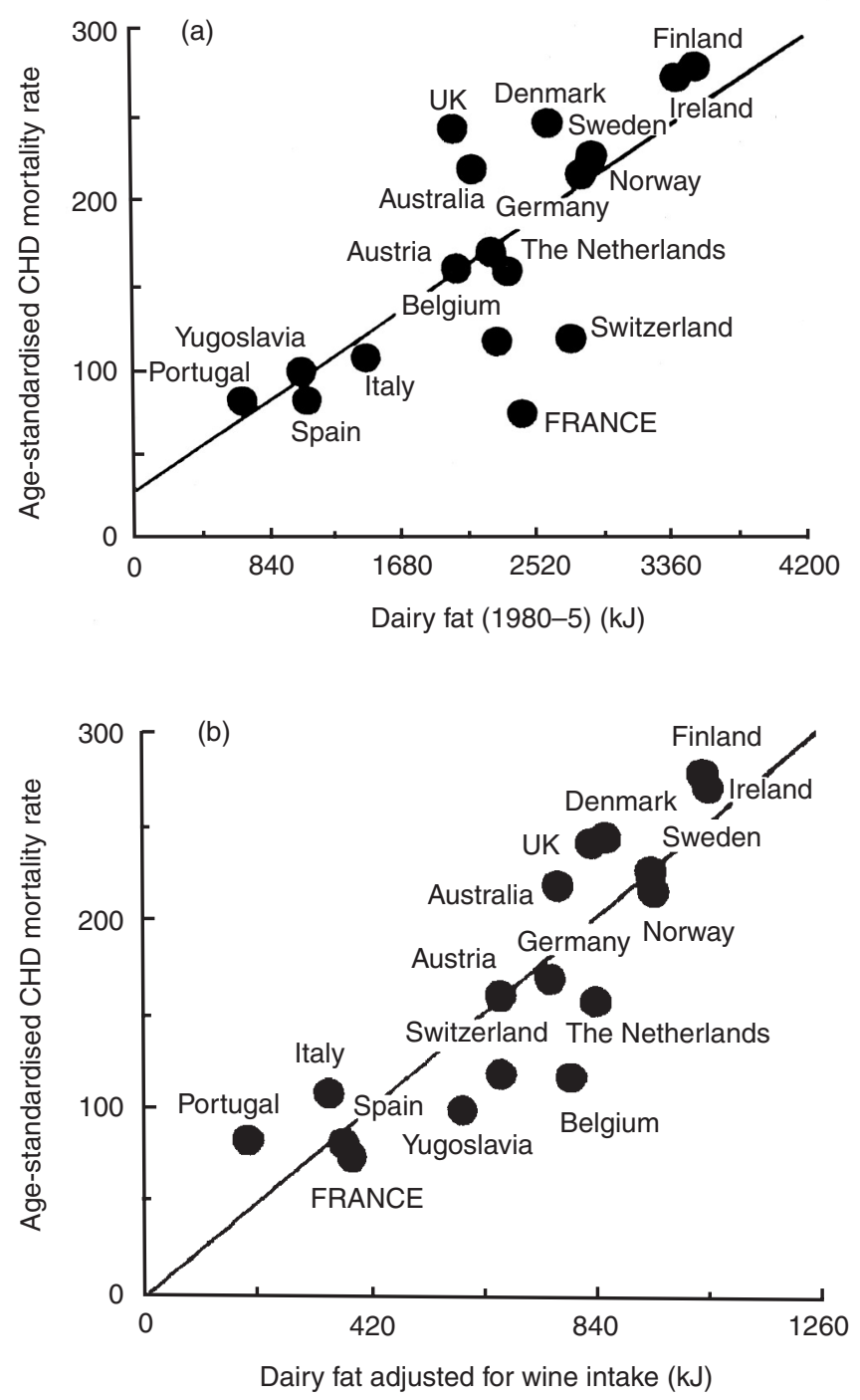

Fig. 2. Relationship between age-standardised death rate from $\mathrm{CHD}$ and consumption of dairy fat before (a) and after (b) the inclusion of wine as an additional predictor. (a) Regression equation $y=26 \cdot 3+0.27$ dairy fat, $r 0.73, P<0.001 ;$ (b) regression equation $y=145+0.138$ dairy fat -0.917 wine, $r 0.87, P<0.0001$. (From Renead \& De Lorgeril, 1992; reprinted with permission from Elsevier Science.)

appropriate adjustments for confounders may, in some cases, be possible. In case-control studies the alcohol intake of survivors of myocardial infarction (MI) may be compared with that of a control group. The pivotal point in case-control studies is to select a comparable control group with regard to potentially confounding factors. Ideally, the controls should be identical to the patients who have survived an MI with regard to factors such as social status, dietary habits and physical activity. If these conditions cannot be fulfilled the next best procedure is to adjust the odds ratios for differences in the potential confounders. A recent case-control study compared patients who had survived an MI with age-, sex- and community-matched controls, and 
adjusted for BMI, personality, family history of MI, physical activity, smoking, energy intake and relative intake of saturated fat (Gaziano et al. 1999). Relative risk for MI was lower in regular drinkers compared with non-drinkers, irrespective of whether their preferred beverage type was wine, beer or spirits. Although adjusted relative risk for MI tended to be somewhat higher for beer drinkers than for wine or spirits drinkers, there was no significant difference between the groups. Another case-control study involving beer drinkers found the lowest adjusted MI risk in individuals with a weekly beer consumption of between 4 and 9 litres (Bobak et al. 2000). Furthermore, a case-control study which also controlled for the traditional cardiovascular risk factors indicated that drinking pattern may be very relevant to the impact of alcohol on the risk of MI (McElduff \& Dobson, 1997). In the present study, in concordance with these other studies, men who reported drinking between one and four drinks daily had a lower risk of MI compared with abstainers, and this effect seemed to be independent of the number of days per week on which alcohol was consumed. However, alcohol intake did not protect against MI risk if more than eight drinks were consumed on drinking days, irrespective of the number of days per week drinking occurred, and the men who drank more than thirteen drinks at a time had a higher incidence of MI.

The prospective cohort studies also suggest that alcohol, per se, may have a cardio-protective effect. These studies almost unambiguously find a negative association between selfreported overall alcohol intake and prospective incidences of fatal or non-fatal MI (Marmot, 1984; Paunio et al. 1994). This association has a particularly strong impact on total mortality in older individuals, who constitutionally exhibit a high incidence of cardiac events (Abramson et al. 2001). In a prospective study an inverse relationship between alcohol consumption and incidence of IHD was found only in individuals with a serum LDL-cholesterol $>5 \cdot 25 \mathrm{mmol} / \mathrm{l}$ (Hein et al. 1996). This observation suggests that alcohol has a true cardio-protective effect which may depend on the blood lipid-associated risk of the individual. It is possible that the higher incidence of MI in abstainers may be due to poorer health status of individuals who have given up drinking due to unfavourable effects of alcohol consumption. However, the negative association seems to persist after exclusion of individuals with diseases that increase the risk of MI (Rimm et al. 1991).

There are numerous other confounding factors to consider in cohort studies. Some of them, i.e. smoking, hypertension and intake of saturated fats, may correlate positively with total alcohol intake or intake of specific beverages, while also being positively associated with CHD. These factors would therefore tend to strengthen a negative relationship between alcohol intake and CHD, if they are adjusted for. However, they may also disturb comparisons between beverage types. In some countries a preference for wine may be associated with healthier dietary habits (Tjønneland et al. 1999), and with higher social and educational status. Such confounders have been suggested as an explanation for findings such as those reported in a largescale Danish follow-up study, where wine intake, but not beer or spirits intake, was inversely related to cardiovascular and all-cause mortality (Grønbæk et al. 1995). Overlooked lifestyle and social factors must, however, be very closely related to individual beverage preferences if they are to fully explain such divergence between wine and other beverage types. Confounders may also explain the odd findings in some cohort studies, such as the study of 7735 randomlyselected British subjects (Wannamethee \& Shaper, 1999). In that study regular drinking of wine (one or more drinks weekly) did not provide any additional protection against CHD events at 16-8-year follow-up compared with occasional drinking (only one to two drinks monthly), although this was the case for both beer and spirits. Nevertheless, wine drinkers, both regular and occasional, had a lower CHD risk than individuals who mainly drank beer or spirits. In conclusion, some observational studies seem to suggest that wine may exert a cardio-protective 
effect which is superior to that of other alcoholic beverages; however, the evidence they provide for such a conclusion can be questionable.

\section{The effect of alcohol consumption on atherosclerosis}

Attenuation of atherosclerotic progression may be an important element in the cardio-protective effect of alcohol. An anti-atherosclerotic effect of alcohol has been demonstrated in coronary arteries from rabbits exposed to alcoholic beverages added to a diet with a typical Western macronutrient composition (Klurfeld \& Kritchevsky, 1981). In that study red wine appeared to possess anti-atherosclerotic properties in addition to those of alcohol. A prospective study in human subjects relating reported alcohol intake to 5-year carotid-artery atherosclerotic progression assessed by ultrasound revealed a clear ' $\mathrm{J}$ '-shaped relationship, as those drinking between 1 and $50 \mathrm{~g}$ alcohol/d had a lower risk of atherosclerotic progression compared with abstainers and those with a higher alcohol intake (Kiechl et al. 1998). This relationship was present in both genders, and in both wine and beer drinkers. It also remained after the exclusion of smokers and adjustment for other factors relating to atherosclerosis. However, when individuals with high and low plasma LDL-cholesterol levels were analysed separately only those with high LDL-cholesterol demonstrated a protective effect of alcohol against early atherosclerotic development. This finding is in line with observations of a lack of protection of alcohol drinking against IHD in individuals with a low plasma LDL-cholesterol level (Hein et al. 1996). Although a light to moderate alcohol intake consumed in a regular fashion may counteract atherogenesis, binge drinking may have the opposite effect. This possibility is indicated by a positive association between the 4-year increase in carotid arterial intima-media thickness and the number of drinks per drinking session, after adjustment for total weekly alcohol consumption, found in a Finnish study using ultrasonographic evaluation on 1022 middle-aged men (Kauhanen et al. 1999).

\section{The effect of alcohol consumption on blood lipids}

\section{Plasma triacylglycerol}

It is well established that atherosclerotic progression is linked to the blood lipid profile. It can be predicted that alcohol acutely increases the hepatic release of triacylglycerol as a consequence of the production of redox equivalents by its oxidation. The hypertriacylglycerolaemic effect of alcohol can be demonstrated when it is administered with a meal. Postprandial plasma triacylglycerol level was increased by $15 \%$ when $30 \mathrm{~g}$ alcohol given as wine was compared with mineral water (Veenstra et al. 1990b). This effect of alcohol on blood triacylglycerol was found to be associated with an elevated hepatic VLDL production (Baraona \& Lieber, 1979). However, plasma triacylglycerol was unaffected by the wine when the meal was followed by a $15 \mathrm{~h}$ fasting period. This finding is in accordance with some long-term feeding studies which have failed to find any effect of moderate regular alcohol consumption on fasting plasma triacylglycerols in normal subjects (Hartung et al. 1983; Couzigou et al. 1984; Crouse \& Grundy, 1984; McConnell et al. 1997). However, recent meta-analysis of thirty-five human intervention studies with $>6 \mathrm{~d}$ of alcohol administration revealed that alcohol consumption increased plasma triacylglycerol (Rimm et al. 1999). (It was not explained in this review

whether only studies assessing fasting blood levels were included.) The hyperlipidaemic effect 
may be more pronounced in obese subjects (Crouse \& Grundy, 1984). Some, but not all, crosssectional surveys showed a positive relationship between reported habitual alcohol consumption and fasting plasma triacylglycerol (Gordon et al. 1981; Hulley \& Gordon, 1981).

\section{Total HDL-cholesterol}

Despite having a moderate hypertriacylglycerolaemic effect, alcohol is associated with a prominent increase in HDL-cholesterol. Based on a meta-analysis of thirty-six data records from human alcohol intervention studies it has been estimated that a daily alcohol intake of $30 \mathrm{~g}$ results in an 8.3\% increase in plasma HDL-cholesterol as compared with abstinence from alcohol (Fig. 3; Rimm et al. 1999). In that meta-analysis the source of alcohol (beer, wine or spirits) did not have a significant influence on the results. Furthermore, an effect of the alcohol component in red wine on plasma HDL-cholesterol has been suggested by a 4-week intervention study with sixty-nine healthy middle-aged subjects recently performed at our department, in which administration of normal red wine (36 and $24 \mathrm{~g}$ alcohol/d in men and women respectively), but not an extract from red wine, raised plasma HDL-cholesterol concentration by $6 \%$ (AS Hansen, unpublished results).

Observational data suggest that alcohol increases plasma HDL-cholesterol, and the effect seems to be unrelated to the type of beverage consumed (Brenn, 1986), but may be stronger in men than in women (Taylor et al. 1981). Although it has been suggested that variations in alcohol consumption explain $\leqslant 10 \%$ of the total variation in HDL-cholesterol on a population basis (Gordon et al. 1981), this moderate relationship may be responsible for a substantial part of the apparent inverse relationship between alcohol intake and the incidence of IHD. Results of a prospective study of 1768 elderly men (Langer et al. 1992) suggest that the effect of alcohol in increasing plasma HDL-cholesterol level may explain approximately $50 \%$ of the total cardio-protective effect of alcohol consumption. HDL-cholesterol was also indicated as an

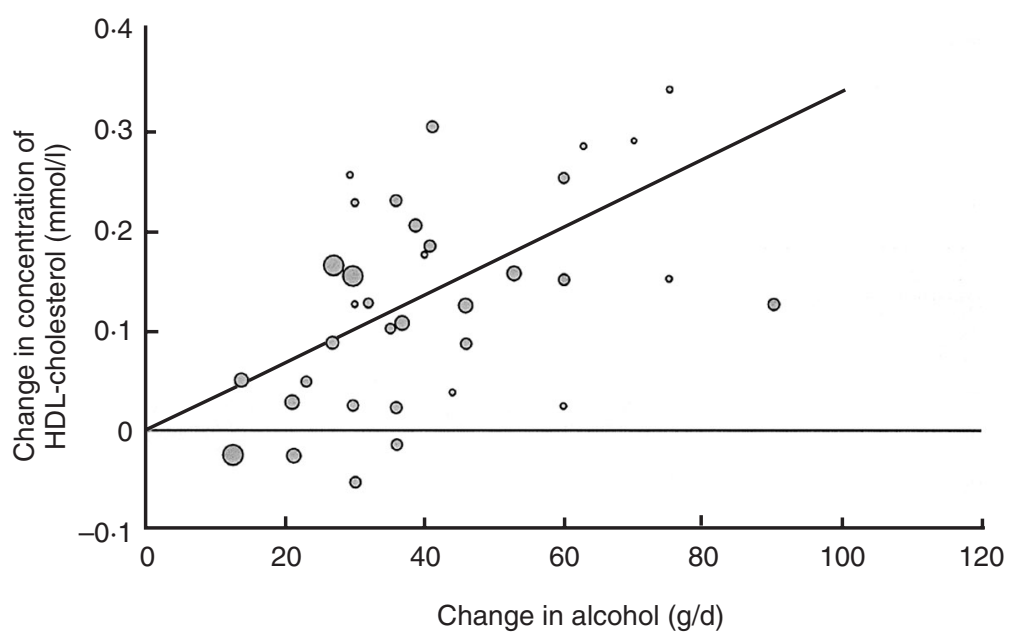

Fig. 3. Between-study association between changes in plasma HDL-cholesterol concentrations and changes in alcohol intake from thirty-six experimental studies. No. of participants: (๑), 1-9; (๑), 10-19; (०), 20-24; (O), ₹25. (From Rimm et al. 1999; reprinted with permission from the BMJ Publishing Group.) 
important mediator of the CHD-preventive effect of alcohol by a case-control study on 340 survivors of MI (Gaziano et al. 1993). In this study the odds ratio for MI was about 0.50 for those individuals who consumed more than one drink daily compared with those who consumed less than one drink monthly. However, the odds ratio increased and became non-significant if variations in HDL-cholesterol were accounted for. In contrast, the odds ratio was virtually unaffected by the inclusion of total cholesterol, LDL-cholesterol or triacylglycerols in the model.

\section{Subfractions of HDL-cholesterol}

There are conflicting results from intervention studies with regard to which subfractions of HDL-cholesterol are increased by alcohol. Some studies found that only $\mathrm{HDL}_{2}$-cholesterol was affected by long-term alcohol administration (Burr et al. 1986; Anonymous, 1987; Veenstra et al. 1990b; McConnell et al. 1997; Rumpler et al. 1999), whereas others reported that only $\mathrm{HDL}_{3}$-cholesterol (Haskell et al. 1984; Sillanaukee et al. 2000), or both $\mathrm{HDL}_{2}-$ and $\mathrm{HDL}_{3}$ cholesterol, were increased (Pikaar et al. 1987). Finally, one cross-sectional study found that reported alcohol intake was positively related to both $\mathrm{HDL}_{2}-$ and $\mathrm{HDL}_{3}$-cholesterol, while another survey found a relationship only with the $\mathrm{HDL}_{3}$ fraction in normal subjects (Sillanaukee et al. 1993). There is some controversy with regard to which HDL subfraction is the strongest inverse predictor of CHD. However, a large prospective study concluded that both fractions seem to be important risk markers (Stamper et al. 1991).

\section{Interactions between alcohol consumption and other lifestyle factors on HDL-cholesterol}

Some studies have compared physically-well-trained and untrained individuals with regard to the effect of alcohol on HDL-cholesterol. In one study alcohol administration increased HDLcholesterol in physically-inactive individuals, but it had no effect in trained subjects who already had a high HDL-cholesterol value during abstinence (Hartung et al. 1983). However, in another study a positive effect of alcohol consumption was observed in both inactive subjects and runners, despite the fact that the runners had a substantially higher baseline HDLcholesterol level (Hartung et al. 1990). Dietary composition may be another factor which plays a role in determining the response of HDL-cholesterol to alcohol. A $3 \%$ increase in HDLcholesterol was observed after 6 weeks with moderate alcohol consumption in non-obese normo-lipidaemic women who were fed a high-fat diet, whereas no such effect of alcohol was observed during low-fat feeding (Rumpler et al. 1999).

\section{Cholesteryl ester transfer protein}

The inverse association between plasma HDL-cholesterol levels and CHD has been explained by HDL-cholesterol being a carrier of cholesterol from the periphery to the liver. Cholesteryl ester transfer protein (CETP) seems to be an important regulatory factor in the exchange of cholesterol for triacylglycerol between HDL and VLDL particles, resulting in a depletion of cholesterol from the HDL particles. That a lowering effect of alcohol on CETP may be responsible for the increase in HDL-cholesterol has been supported by human experiments in which fasting CETP activity in plasma was found to be lower in alcoholics (Savolainen et al. 1990; 
Hagiage et al. 1992) and in normal subjects after a 2-week period with a daily alcohol intake of $30 \mathrm{~g}$ (Hagiage et al. 1992). However, other studies have not found a decreased CETP activity in subjects with a moderate alcohol consumption (Nishiwaki et al. 1994; Hendriks et al. 1998), and the high plasma HDL-cholesterol level associated with alcohol consumption may not be entirely the result of a low CETP activity.

\section{Other possible factors involved in the augmentation of HDL-cholesterol}

The formation of HDL-associated apoproteins may be promoted, since plasma concentrations of apoproteins A-I and A-II in normal subjects have been reported to be increased after 2 weeks on a daily intake of $30 \mathrm{~g}$ alcohol (Hagiage et al. 1992). Furthermore, an enhancing effect of alcohol on lipoprotein lipase (LPL) activity has been proposed as a mechanism by which alcohol increases HDL-cholesterol (Nishiwaki et al. 1994). Associations between variations in the LPL gene and plasma levels of triacylglycerol and HDL-cholesterol (Razzaghi et al. 2000) suggest that LPL activity may be a determinant for blood HDL-cholesterol. This possibility could be explained if the supply of surface molecules for HDL particles is rate-limiting for their formation, as VLDL particles may deliver such components after being degraded by LPL.

\section{The beneficial effect of alcohol on reverse cholesterol transport is questioned}

Although HDL-cholesterol is increased and CETP activity may be reduced with regular alcohol consumption, this situation does not necessarily ensure greater protection against infiltration of cholesterol into the arterial wall. The efflux capacity of cholesterol from HDL particles to liver cells, evaluated by measuring the delivery of pre-labelled cholesteryl oleate from HDL to cultured human hepatoma cells, has been found to be reduced by $83 \%$ in alcoholics without liver disease compared with non-alcoholics (Rao et al. 2000). This finding could mean that the high concentration of HDL is counteracted by each HDL particle having a lower capacity to mediate reverse transport of cholesteryl esters. Furthermore, the decline in CETP activity with alcohol consumption, which has been observed in the fasting state, may not apply to the acute effects of alcohol, as an increased net mass transfer of cholesteryl esters from HDL to VLDL has been reported where wine was served with a meal as compared with mineral water (Van Tol et al. 1995). This observation may be a result of an increased plasma triacylglycerol level.

Reverse cholesterol transport may not be the only mechanism by which HDL prevents atherosclerotic plaque formation. HDL particles may contain enzymes that could inhibit LDL oxidation (Berliner et al. 1995). Furthermore, as explained earlier, a high plasma HDL level may reflect increased LPL activity. Low LPL activity may be associated with high formation of small atherogenic LDL particles (Hokanson et al. 1999). Also the plasma level of total LDLcholesterol is not consistently reduced by alcohol (Savolainen \& Kesäniemi, 1995).

\section{The role of alcohol consumption in CHD relating to lipid metabolism depends on genetic factors}

The interplay between alcohol consumption, HDL-cholesterol, CETP function and CHD may be strongly influenced by genetic factors. In one study a polymorphism in the CETP gene was 
found to be associated with plasma HDL-cholesterol level, but only in individuals drinking more than $25 \mathrm{~g}$ alcohol/d (Fumeron et al. 1995). When the protective effect of alcohol against MI was tested, it was found that this effect was more pronounced in the genotype associated with the highest HDL-cholesterol levels. Somewhat in contrast to these results, a more recent study on another polymorphism in the CETP gene showed that the intima-media thickness of the carotid artery paradoxically was greatest in the genotype associated with the lowest CETP activity and highest HDL-cholesterol level; however, only in individuals with a high alcohol consumption (Kakko et al. 2000). These studies imply that there could be an interaction between the influence of alcohol in the development of atherosclerosis and genetic variations in CETP. An intetraction has also been shown between the effect of alcohol on HDL-cholesterol and CHD and polymorphisms in other genes.

One of the isoenzymes of alcohol dehydrogenase (ADH3) has a polymorphism which influences the rate of alcohol oxidation. The increase in HDL associated with moderate drinking was found to be most pronounced in those individuals who were homozygous for the allele related to the lowest alcohol degradation rate, and in these men it was also found that alcohol had the greatest protective effect against the development of MI (Hines et al. 2001). The latter effect could not be explained entirely by the effect on HDL-cholesterol, which suggests that other factors may contribute to the cardio-protective effect of alcohol. Findings that genetic factors affecting alcohol metabolism also influence the relationship between alcohol consumption and CHD are important, because they point to a true impact of alcohol, since such relationships are not likely to be confounded by social and lifestyle factors. In conclusion, the data compiled indicate very convincingly that alcohol, per se, has an overall impact on blood lipids which may protect against cardiovascular disease. However, the relative atherogenic potential of the different cholesterol-carrying lipid fractions is still under debate, as other fractions in addition to LDL- and HDL-cholesterol may be independent predictors for the development of CHD (Grundy, 2001). Further general understanding of cholesterol exchange in relation to vascular infiltration, seems to be necessary therefore, in order to elucidate satisfactorily how alcohol may convey a beneficial effect on blood lipids.

\section{Effect of alcoholic beverage consumption on blood platelet aggregation}

\section{In vivo studies}

Acute studies with moderate doses of alcohol have reported reduced platelet aggregation in whole blood or platelet-rich plasma after different stimuli (Mikhailidis et al. 1987; Numminen et al. 2000a; Zhang et al. 2000). However, the efficacy of alcohol in inhibiting platelet aggregation seems to be sensitive to the stimulating agent used and to the fatty acid composition of the platelet plasma membrane (Fenn \& Littleton, 1982). Thus, aggregation after treatment with collagen and thrombin was reduced more by ethanol if the platelets were enriched with saturated fatty acids (Numminen et al. 2000a). This finding agrees with the observation from a cross-sectional study in which individuals with a high habitual intake of saturated fat exhibited a closer negative relationship between reported alcohol intake and platelet aggregation responses to different stimulating agents than subjects with a low habitual intake (Renaud et al. 1992).

Observational studies (Meade et al. 1985; Serebruany et al. 2000) and long-term intervention studies (Pikaar et al. 1987; Bierenbaum et al. 1994) support the existence of a negative effect of moderate alcohol consumption on platelet aggregation. However, when given in large 
amounts $(1.5 \mathrm{~g} / \mathrm{kg})$ alcohol may promote platelet aggregation, since an increased urinary excretion of thromboxane B2 has been observed (Numminen et al. 2000b). This paradoxical effect might be a result of secondary effects such as a high generation of reactive oxygen species.

A marked rebound in platelet aggregatibility, which is associated with alcohol withdrawal in alcoholics (Hillbom et al. 1985), may constitute an increased risk for sudden cardiac death. This phenomenon is apparently abolished if the alcohol is consumed as red wine, and may be a result of the phenolic compounds in the wine (Ruf et al. 1995).

\section{The effect of alcohol itself}

Incubation studies support a platelet-suppressing effect of alcohol. When isolated platelets exposed to collagen are incubated with physiological concentrations of ethanol the formation of thromboxane B2 is attenuated in a dose-dependent fashion (Rubin, 1989). A reduction in the release of arachidonic acid, the substrate for thromboxane, is observed. This reduction may be due to inhibition of phospholipase A2 by ethanol (Stubbs \& Rubin, 1992), which could reduce the release of arachidonic acid from phopholipids. That ethanol has been observed to inhibit the secondary thromboxane-dependent aggregation phase, but not the primary phase, suggests that an attenuated thromboxane formation is involved (Rand et al. 1988).

\section{Non-alcohol factors}

Reactive oxygen species act as autocrine agents for blood platelets to stimulate their phospholipase activity and thromboxane production (Leo et al. 1997). Antioxidants such as phenolic substances in beverages may therefore act in concert with alcohol to inhibit platelet aggregation. Antioxidants such as phenolic compounds in the alcoholic beverages could therefore have contributed to the inhibitory effect on platelet activity found in alcohol-consumption studies. Nonalcohol factors may in particular explain findings from observational studies in which platelet aggregation was in most cases assessed in fasting blood drawn $>12 \mathrm{~h}$ after the last drink, where it is more likely that the effects of substances with a longer half-life than ethanol were being tested. The presence of other substances in red wine with an anti-aggregative effect has been suggested by a study in which both red wine and grape juice at low concentrations were demonstrated to abolish a flow reduction induced by platelet aggregation. This effect was demonstrated by the application of the so-called Folts model, in which stenosis of a coronary artery is introduced mechanically to produce cyclic flow reduction (Demrow et al. 1995). White wine was found to be less effective. Trans-resveratrol and quercetin may be the active polyphenols in red wine and grape juice, as they have been demonstrated to inhibit both ADP- and thrombin-induced platelet aggregation when added to platelet-rich plasma. By contrast, ethanol was only able to inhibit thrombin-induced platelet aggregation in this preparation (Pace-Asciak et al. 1995). The effect of trans-resveratrol was associated with a reduction in thromboxane B2 formation. In contrast to white wine, red wine is rich in resveratrol, as this polyphenol is present in high concentrations in grape skin. After 4 weeks of administration of resveratrol-enriched grape juice inhibition of thrombin-induced platelet aggregation was observed, which indicates that at least part of the antihaemostatic effects of polyphenols is not conditioned by concurrent intake of alcohol (PaceAsciak et al. 1996). However, de-alcoholised red wine, in contrast to untreated red wine or pure alcohol in fruit juice $(30 \mathrm{~g} / \mathrm{d})$, was not found to reduce collagen-induced platelet aggregation in blood from fasting subjects following a 4-week supplementation period (Pellegrini et al. 1996). 


\section{Effects of alcohol consumption on coagulation and fibrinolysis}

Alcohol may also affect the tendency to thrombus formation by interfering with enzymes and other proteins involved in thrombogenesis and fibrinolysis.

\section{Plasminogen activation}

Plasminogen activator inhibitor-1 (PAI-1) inhibits tissue-type plasminogen activator (t-PA), which converts plasminogen to the fibrinolytic enzyme plasmin. By this mechanism PAI-1 is the major controlling factor for fibrinolytic activity. Fibrinolysis is not only important in acute thrombolytic function, but also occurs in the atherosclerotic plaque, and may therefore retard the progression of atherosclerosis, as fibrin constitutes a crucial part of the plaque structure.

A recent prospective case-control study which compared patients who subsequently experienced their first MI with a matched reference group suggests that a high PAI-1 level may be associated with a high risk of CHD (Thögersen et al. 1998). Ethanol concentrations as low as $0.2 \%(\mathrm{v} / \mathrm{v})$ have been demonstrated to increase the secretion of t-PA from cultured endothelial cells (Laug, 1983). Nevertheless, when $40 \mathrm{~g}$ alcohol was given with the evening meal the activity of t-PA was found to be reduced acutely, despite the increase in its blood concentration (Hendriks et al. 1994). This response was a result of a substantially increased PAI-1 activity, and was observed irrespective of the alcohol source (beer, wine or spirits). However, on the following morning t-PA concentration remained elevated whereas PAI-1 had returned to the basal level; these responses after alcohol resulted in higher plasminogen activity at that time (Hendriks et al. 1994). It was hypothesised that such a situation constitutes an overall protective effect against cardiac attacks, as these attacks are most likely to occur in the morning. In another study with a similar design increased PAI activity, accompanied by reduced t-PA activity in the postprandial phase, was also found after $30 \mathrm{~g}$ alcohol, but in that study no overshoot in t-PA activity was detected the next morning (Veenstra et al. 1990a). Apparently doses as low as $20 \mathrm{~g}$ do not interfere with PAI-1 and t-PA activity (van de Wiel et al. 2001). Larger doses of alcohol ( $>40 \mathrm{~g}$ ) seem to exert a marked inhibiting effect on the fibrinolytic system. In this case, the increase in PAI-1 has been found to be very pronounced and to persist the following morning (Fig. 4; Numminen et al. 2000b; van de Wiel et al. 2001). With $80 \mathrm{~g}$ alcohol clot lysis time was increased by 151 and $73 \% 5 \mathrm{~h}$ after alcohol consumption and the next morning respectively (van de Wiel et al. 2001).

The chronic effect of regular alcohol consumption on overnight fasting fibrinolytic variables has been tested in several studies. No effects on $12 \mathrm{~h}$ fasting blood levels were found for t-PA and PAI-1 antigens or activities with a daily alcohol intake of $13.5 \mathrm{~g}$ (beer compared with abstention) after a 6-week intervention period (McConnell et al. 1997). Accordingly, no change in t-PA antigen was found in fasting blood after 4 weeks on a daily intake of $30 \mathrm{~g}$ alcohol from red wine or dissolved in fruit juice (Pellegrini et al. 1996). These findings agree with a metaanalysis of studies involving alcohol intervention, which shows no significant effect on t-PA antigen of alcohol consumption normalised to $30 \mathrm{~g} / \mathrm{d}$ (Rimm et al. 1999). However, in one 4week intervention study a greater increase in PAI-1 than t-PA was found with alcohol consumption, indicating a decline in total t-PA activity (Dimmitt et al. 1998). In cross-sectional studies a positive association between reported alcohol consumption and t-PA concentration has been observed, which persisted after adjustment for some relevant confounders such as overall atherosclerotic progression, blood pressure, plasma triacylglycerol level and BMI (Ridker et al. 1994; Lee et al. 1995). However, PAI-1 and t-PA activity were not measured in these studies. 

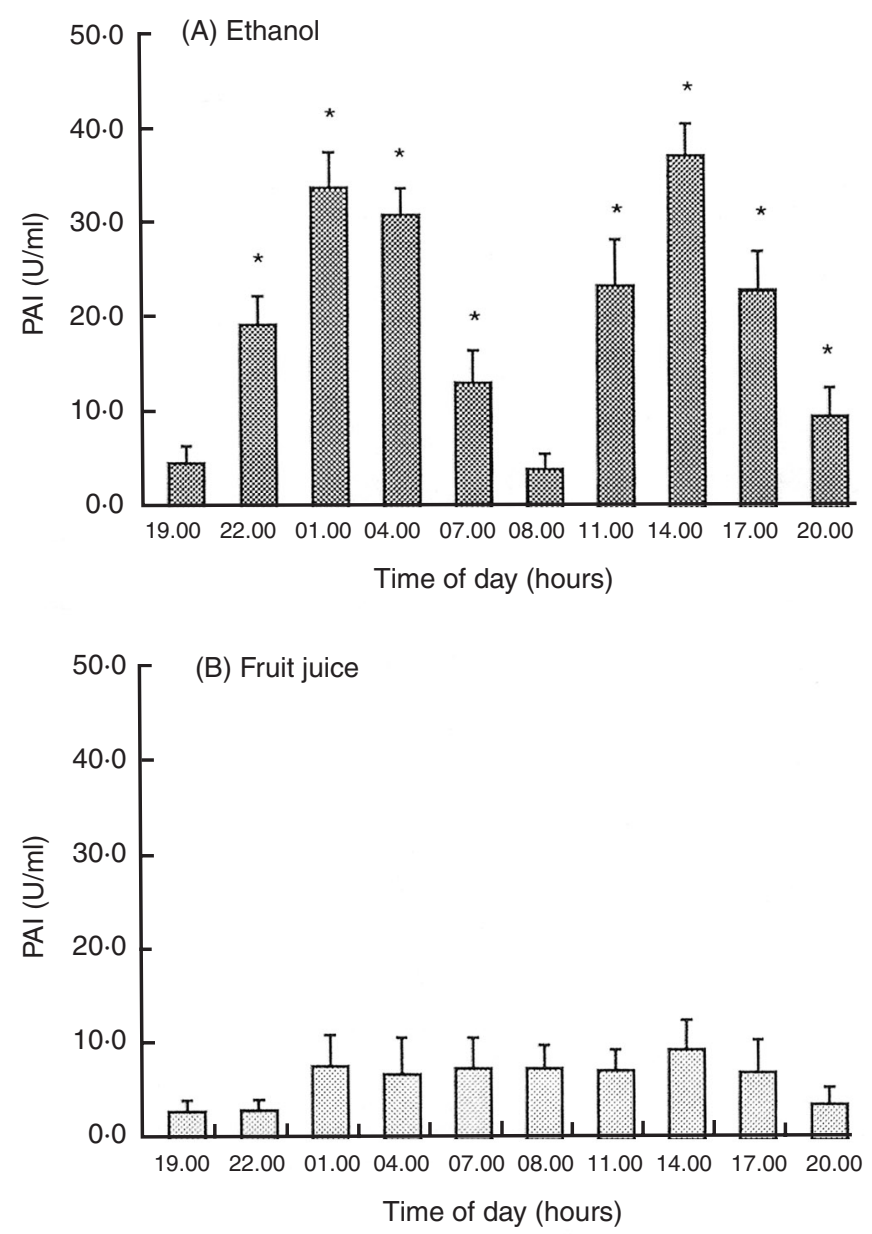

Fig. 4. Effect of acute ingestion of large doses of ethanol $(1.5 \mathrm{~g} / \mathrm{kg}$ body weight in fruit juice) on plasminogen activator inhibitor (PAl-1) activity throughout the day and night. Values are means with their standard errors represented by vertical bars. Mean values were significantly different from the respective baseline values $(n 12):{ }^{*} P<0 \cdot 05$. (From Numminen et al. 2000b; reprinted with permission from Lippincott Williams \& Wilkins.)

\section{Additional effects on haemostasis}

Alcohol may also interfere with the function of other proteins involved in the haemostatic mechanism. A recent meta-analysis based on twenty-two different investigations, including eight prospective studies on healthy men, has established fibrinogen level as an independent predictor of CHD (Maresca et al. 1999). Alcohol in moderate amounts has been demonstrated to diminish fibrinogen production from isolated hepatoma cells by impairment of gene transcription, and to reduce plasma fibrinogen concentration when fed to rats (van Golde et al. 1999). Some human intervention studies have demonstrated a decline in plasma fibrinogen with alcohol consumption, and part of the cardio-protective effect of alcohol may therefore be explained by this mechanism. In one study 4 weeks of consumption of red wine or alcohol in fruit juice $(30 \mathrm{~g} / \mathrm{d})$ was found to lower plasma fibrinogen concentration; an effect not found 
with de-alcoholised wine (Pellegrini et al. 1996). In contrast, in another study there was no change in fibrinogen level after a $30 \mathrm{~d}$ period on a daily intake of $20 \mathrm{~g}$ alcohol as beer (Gorinstein et al. 1997b). These results are in agreement with cross-sectional data showing lower fibrinogen levels in individuals drinking $<60 \mathrm{~g}$ alcohol as wine or spirits than in abstainers, whereas beer drinking did not have this effect (Mennen et al. 1999). The authors suggested that other substances in beer had a counteracting effect. However, that alcohol in beer can suppress plasma fibrinogen level was indicated by an increase in fibrinogen when regular beer drinkers had their ordinary beer substituted by de-alcoholised beer for a 4-week period (Dimmitt et al. 1998).

The impact of alcohol on coagulation factors was investigated in a cross-sectional study which found a negative relationship between reported alcohol intake and factor VII (Lee et al. 1995). Both reduced (Gorinstein et al. 1997b) and increased (Dimmitt et al. 1998) levels have been found in experimental studies.

Based on these studies it is difficult to reach a conclusion as to whether the net effect of alcohol on coagulation and fibrinolysis is cardio-protective. The 'U'-shaped relationship between alcohol intake and plasma fibrinogen level (Mennen et al. 1999), together with the enhancing effect of high doses of alcohol on PAI-1 activity, may explain the apparent increased risk of cardiac events in individuals with a gorging pattern of alcohol consumption (McElduff \& Dobson, 1997). An area which has received little attention is the possible effects that other substances in the alcoholic beverages may exert on coagulation. Red wine may affect coagulation via its polyphenols, such as resveratrol which has been found to inhibit the response of tissue factor transcription to different stimulating agents when given as a pre-incubate to isolated endothelial cells (Pendurthi et al. 1999). Release of tissue factor is the first step in one of the pathways leading to activation of the coagulation cascade.

\section{The pro- and antioxidant effects of alcohol and alcoholic beverages}

Oxidative stress exerted by reactive oxygen species may be critical for the development of $\mathrm{CHD}$, and this process may be mediated through several mechanisms. Both prospective and case-control studies have shown negative associations between antioxidant intake, particularly $\alpha$-tocopherol, and CHD (Diaz et al. 1997; Hooper et al. 2001), which indicates that reduced oxidative stress may be protective against cardiac events. Vitamin deficiency associated with excessive drinking could therefore be detrimental for the heart. However, moderate intake of alcoholic beverages with a high content of antioxidant vitamins may improve their status in the body. For example, a regular beer intake has been found to increase blood $\alpha$-tocopherol concentration after $30 \mathrm{~d}$ (Gorinstein et al. 1997a).

\section{The antioxidant role of phytochemicals and their interactions with alcohol}

In addition to antioxidant vitamins, different phytochemicals may also provide protection against oxidative stress. In in vitro studies some of these compounds have been found to be more efficient than tocopherol in protecting LDL against oxidation (Vinson et al. 1999). In a cross-cultural correlation study an inverse association was found between flavonoid intake and the 25-year follow-up age-adjusted incidence of CHD mortality. Flavonoid intake could explain $8 \%$ of the variation in CHD in a model where dietary saturated fat and percentage of smokers explained 73 and $9 \%$ of the variation respectively (Hertog et al. 1995). In another study a risk 
ratio of 0.32 for 5 -year incidences of MI was found when elderly individuals within the higher and lower tertiles of flavonoid intake were compared (Hertog et al. 1993). In this study confounders such as age, BMI, smoking, physical activity, coffee consumption and intakes of ascorbic acid, vitamin E, $\beta$-carotene and dietary fibres were accounted for. To our knowledge no long-term randomised intervention studies have been conducted to address a possible cardio-protective effect of isolated antioxidant phytochemicals.

Alcohol and antioxidants in alcoholic beverages may modulate the oxidative stress exerted on blood and endothelium. The effect of alcohol itself on oxidative stress may be double-edged. Alcohol can generate reactive oxygen species, particularly in the liver, but also in other organs (Trevithick et al. 1999), and the increased serum concentration of Mn-superoxide dismutase in alcoholics may reflect the fact that they are exposed to a greater oxidative stress (Thome $e t$ al. 1997). However, at the same time alcohol may act as a superoxide and peroxide scavenger (Mantle \& Preedy, 1999). Moreover, when alcohol acts in concert with the other substances present in vastly varying concentrations even within the same drink category, the net effect on oxidative stress may be difficult to predict. Furthermore, bioavailibility and metabolic modification of the antioxidants are important factors that may determine their biological impact. Finally, pro-oxidant and antioxidant activities appear, to some extent, to be specifically related to the different cardio-protective mechanisms. Hence, in relation to the protection of LDL particles from oxidation, the lipophilic characteristics of the antioxidants, and hence their ability to bind to the lipoproteins, may be crucial.

The research into antioxidant effects of particular substances in alcoholic beverages has been focused on red wine, because it is rich in a variety of phenolic compounds with antioxidant capacities (Ghiselli et al. 1998). However, beer contains highly-absorptive monophenols such as ferulic acid (Bourne et al. 2000), and prenylated flavanones and chalones with potent protecting effects against $\mathrm{Cu}^{2+}$-catalysed oxidation of isolated LDL (Miranda et al. 2000). Interestingly, lager beer has been reported from in vitro studies to be a stronger inhibitor of LDL + VLDL oxidation than de-alcoholised Bordeaux red wine (Vinson et al. 1999). However, if the beverages were mixed with human plasma before the isolation and testing of the lipoprotein particles, the beer provided much less antioxidative protection than the red wine. This finding suggests the importance of testing the oxidant effects of different phytochemicals in an ex vivo system.

The acute effect of red wine on serum antioxidant capacity has been assessed by luminescensce measurements after reactive oxygen species had been generated in serum by adding horseradish (Armoracia rusticana) peroxidase and sodium perborate. An increase in serum antioxidant capacity was seen after the ingestion of $300 \mathrm{ml}$ red wine, which was comparable with the increase after intake of $1000 \mathrm{mg}$ ascorbic acid (Whitehead et al. 1995). White wine was observed to have a lesser effect on serum antioxidant capacity. Increased serum antioxidant capacity after red wine intake has been confirmed by other methods (Cao et al. 1998), and also with de-alcoholised red wine (Serafini et al. 1998). The presence of alcohol in beverages may improve the bioavailability of phenolic compounds, as ethanol may act as a carrier for the absorption of such substances, which are poorly water soluble. This factor may explain why normal beer but not de-alcoholised beer was found to increase plasma concentrations of some phenolic acids (Ghiselli et al. 2000). Accordingly, plasma antioxidant capacity was increased $1 \mathrm{~h}$ after the ingestion of normal beer, whereas the response to de-alcoholised beer was attenuated and non-significant.

Acute studies on plasma retrieved after single doses of different beverages, or tests where the antioxidant capacity of the beverage was tested directly, may not reflect the responses to long-term regular intake. When tested directly red wine was found to have more than twice the 
antioxidant capacity of beer for a given quantity of alcohol, whereas no antioxidant properties could be detected in spirits (van der Gaag et al. 2000b). However, when plasma antioxidant capacity was tested by the same method after 3 weeks on a daily intake of $40 \mathrm{~g}$ alcohol as wine, beer or spirits, no differences were seen between the beverages. Furthermore, there was no difference in the antioxidant capacity of any of the beverages after the test period when compared with mineral water. In accordance with this finding, 6 weeks of dietary supplementation with pure alcohol or beer was found to have no effect on lipid peroxidation in rats (Gasbarrini et al. 1998). These observations may be explained by the fact that the total effect on blood antioxidant capacity is due not only to the antioxidants in the beverages, per se, but also to more chronic alterations in other substances which may influence the general antioxidant environment in the plasma. Thus, alcohol may have some secondary negative effects on antioxidants in the blood, e.g. plasma ascorbic acid concentration may decline as a result of moderate regular alcohol consumption (van der Gaag et al. 2000b).

\section{The endothelial function}

One important mechanism by which reactive oxygen species may promote cardiovascular diseases is impairment of endothelial function by interference with the generation of NO. Alcohol and substances in alcoholic beverages may influence the NO systems by their pro-oxidant and antioxidant properties. However, more specific mechanisms may also be involved.

Oxidative stress may cause superoxide radicals to react with NO to form peroxynitrite $\left(\mathrm{ONOO}^{-}\right)$and therefore impair NO-related endothelial functions such as vasodilation, inhibition of platelet aggregation and down-regulation of the apoptosis of the endothelial cells themselves. Furthermore, $\mathrm{ONOO}^{-}$is cytotoxic, and under some conditions it may enhance platelet aggregation (Moro et al. 1994). Antioxidants may prevent this process. Thus, the degradation of NO produced by endothelial cells can be inhibited by superoxide dismutase, which is a superoxide scavenger (Gryglewski et al. 1986). S-allyl cysteine, a strong antioxidant present in garlic (Allium sativum), has been demonstrated to increase cyclic guanosine 5'-monophosphate production in cultured endothelial cells, indicating a greater bioavailability of NO (Kim et al. 2001). Phenolic substances in red wine may have similar NO-conserving effects, as red wine and extracts from grape skin have been reported to elicit dilation in rat aorta preparations, an effect which could be abolished by competitive inhibition of NO synthesis (Fitzpatrick et al. 1993). These results have been replicated more recently in coronary artery preparations obtained from myopathic hearts from patients undergoing heart transplantation (Flesch et al. 1998). Interestingly, the latter study tested several different brands of wine and found that only red wines fermented with the grape stems induced vasodilation. It was hypothesized that the tannic acid, which was present in high concentrations in these brands, was the most important vasoactive substance. This finding was subsequently supported by the demonstration that tannic acid by itself could also trigger endothelial-dependent vasodilation. However, it was not directly demonstrated in these studies that the vasodilating effect of the wine substances was due to superoxide scavenging. It is questionable as to what extent these in vitro studies can be extrapolated to in vivo conditions, especially because the bioavailability of the different phenolic substances is uncertain. However, in one recent investigation flowmediated vasodilation, as a measure of endothelial function, was greater after $30 \mathrm{~d}$ on a daily intake of $240 \mathrm{ml}$ red wine (Cuevas et al. 2000). Furthermore, this effect was most pronounced in subjects who consumed a high-fat diet, which resulted in a lower basal arterial responsiveness (Fig. 5). In addition to these effects of the phytochemicals, alcohol may promote endothe- 
(A)

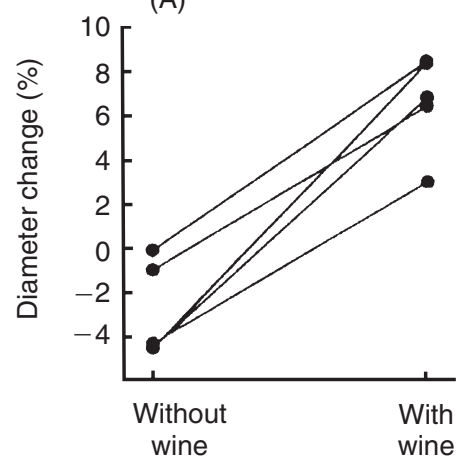

(B)

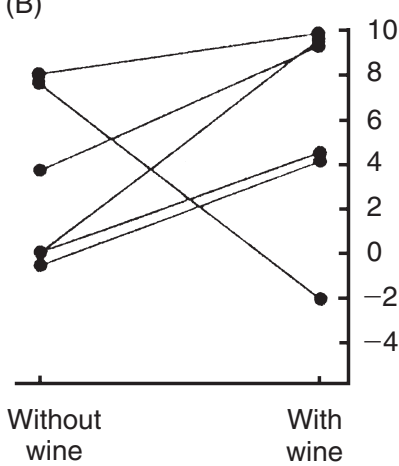

Fig. 5. Effect of $30 \mathrm{~d}$ of wine supplementation on individual flow-mediated vasodilation in the brachial artery (expressed as percentage change in arterial diameter relative to the diameter before circulatory arrest) in subjects consuming either a high-fat (A) or control (B) diet. (From Cuevas et al. 2000; reprinted with permission from AOCS Press.)

lial NO production, as it has been reported to promote NO synthase (NOS; eNOS isoform) mRNA and protein expression, and to stimulate NO production by a specific, but not yet clarified, mechanism when added in physiological concentrations in endothelial cells (Venkov et al. 1999).

It is also possible that substances in alcoholic beverages may have the capacity to affect the endothelial mechanisms by an impact on the metabolism of the amino acid methionine. Homocysteine, which is generated by demethylation of methionine in the liver, is able to impair endothelial function if it is present in elevated concentrations in the plasma. In vivo endothelial function has been demonstrated to respond to a raised plasma concentration of L-arginine in terms of a reduction in blood pressure and platelet aggregation (Nappo et al. 1999), which could be explained by enhanced NO production. These effects were found to be abolished, however, after methionine-induced hyperhomocysteinaemia, but could be re-established by antioxidant vitamins (ascorbic acid + vitamin E). In the same study methionine loading was also demonstrated to shift haemostatic variables towards coagulation. This effect could also be attenuated by antioxidant vitamins.

There are data that suggest that more moderately elevated homocysteine levels are also associated with an impaired endothelial function independently of BMI, blood pressure and plasma folate, vitamin $\mathrm{B}_{12}$ and cholesterol levels in individuals without any symptoms or history of cardiovascular disease (Woo et al. 1997). However, the importance of variations in plasma homocysteine within the normal range as a risk factor for the development of CHD in healthy individuals is debatable because elevated plasma levels of homocysteine could be a marker of a generally unhealthy lifestyle (Cleophas et al. 2000), or they may be a consequence of vascular damage, which may impair renal function (Brattstöm \& Wilcken, 2000).

At present there is some, although not very robust, evidence that a high intake of folic acid and vitamin $\mathrm{B}_{6}$ might have some cardio-protective effects through reduced homocysteine formation (Rimm et al. 1998; Vermeulen et al. 2000). Alcohol, per se, and also the vitamin $\mathrm{B}_{6}$ and folate contents of the beverages, may affect plasma homocysteine level. Moderate intake of red wine and spirits (40 $\mathrm{g}$ alcohol/d) has been reported to increase plasma homocysteine level after 3 weeks in healthy men fed a controlled diet (van der Gaag et al. 2000a), an effect which may be due to alcohol itself. However, if the same amount of alcohol was provided as beer no such 
effect was observed. This difference could be attributable to a concurrent rise in blood vitamin $\mathrm{B}_{6}$ concentration, which was greater after beer than after wine and spirits. The marked effect of beer on plasma vitamin $\mathrm{B}_{6}$ level can be explained by the high vitamin $\mathrm{B}_{6}$ content of beer in contrast to wine and spirits. A modest relative hypohomocysteinaemic effect of beer (9\%) compared with wine and spirits may be minor compared with the other cardiac effects of alcoholic beverage drinking. However, in the case of excessive alcohol consumption, beer drinking may protect against the vitamin B deficiency frequently found in alcoholics and therefore also against hyperhomocysteinaemia. Thus, in a mainly beer-drinking society, serum levels of folate were found to be higher and those of homocysteine to be lower in individuals who had a daily intake of more than $28 \mathrm{~g}$ alcohol/d compared with those who drank less than $4 \mathrm{~g}$ alcohol/d (Mayer et al. 2001).

\section{Macrophage activity}

The cardio-protective role of antioxidant intake may also involve NO effector systems other than that related to endothelial NO production. In contrast to the paracrine effects of small amounts of NO produced in the endothelium by the eNOS isoform, macrophages produce large quantities of NO by inducible NOS (iNOS isoform), which acts cytotoxically to destroy pathogens as part of the inflammatory process. Endothelial damage caused by high concentrations of NO produced by macrophages is probably an important element in the atherosclerotic process. Oxidant stress may contribute to this destructive process by promoting macrophage production of NO. The hydroxyl radical has been demonstrated to activate nuclear factor $\mathrm{\kappa B}$, which is a transcription factor for the iNOS gene (Chen et al. 1998). Antioxidants may therefore counteract plaque formation by attenuating inflammatory attacks on the arterial wall. The role of antioxidants in alcoholic beverages on the iNOS system in vivo is not well elucidated. However, resveratrol and quercetin have been demonstrated to inhibit NO production from cultured macrophages stimulated by $\gamma$-interferon or lipopolysaccharide, an effect associated with a reduction in the expression of the iNOS gene (Chan et al. 2000). The latter effect was potentiated by the addition of ethanol. However, ethanol concentrations of $>0.5 \%(\mathrm{v} / \mathrm{v})$ were required to achieve an appreciable synergistic effect. In addition to the impact on macrophage NO production, these polyphenols were found to act as NO scavengers.

Another important anti-atherosclerotic function of antioxidants is that of counteracting LDL oxidation, which has been proposed to play a crucial role in plaque formation. Oxidised LDL stimulates the endothelium to produce different factors which attract and bind monocytes and promote their migration into the subendothelial space (Berliner et al. 1995). Here they are converted into macrophages with a great capacity to infiltrate cholesterol into the arterial wall, where it constitutes an important part of the plaque. Furthermore, oxidised LDL particles are highly susceptible to being taken up by these macrophages, as they are recognised by the scavenger receptor which, in contrast to the LDL receptor, is not down regulated by negative feedback mechanisms (Parthasarathy et al. 1992). Moreover, some of their modified phospholipids may act as a mitogenic factor for smooth muscle cells, and thereby promote the formation of the plaque (Heery et al. 1995). Finally, it has been suggested that antibodies directed against oxidised LDL may cross-react with similar oxidatively-modified membrane structures in thrombocytes, and thereby affect their thrombogenic activity (Witztum \& Hörkkö, 1997). As LDL is oxidised by reaction with free radicals, antioxidants that scavenge free radicals inhibit LDL oxidation, and may therefore protect against vascular damage. 
Alcohol feeding to rodents has been reported to both increase (Xia et al. 1998) and decrease (Mantle \& Preedy, 1999) the susceptibility of isolated plasma LDL particles to become oxidised. Moreover, an inhibiting effect of red-wine polyphenols has been documented directly in a system where isolated human LDL particles were oxidised by $\mathrm{Cu}^{2+}$ (Frankel et al. 1993). In one human experiment, a daily intake of $375 \mathrm{ml}$ of red wine for 2 weeks led to greater propensity for the LDL to become oxidised, despite the fact that the LDL became more resistant to oxidation when directly incubated in red wine (van Golde et al. 1999). The latter finding suggests that, in relation to LDL oxidation, the pro-oxidant effects of the alcohol in wine may have overshadowed the antioxidant effects of its other constituents under in vivo conditions. The poor in vivo effect of the antioxidant substances in wine relative to the effect observed in vitro was suggested to be due to low bioavailability. However, in another 2-week wine consumption study (Fuhrman et al. 1995) red wine was, in fact, found to decrease the susceptibility of LDL to be oxidised. This discordance may be explained by differences in available polyphenols in the different red wines used. The pro-oxidant effect of alcohol was also demonstrated in the latter study, as plasma lipids and LDL were found to be less resistant to oxidation after white wine consumption for 2 weeks (Fig. 6).

A third factor which may contribute to the net effect on lipid oxidation of drinking an alcoholic beverage is uric acid, which has been demonstrated to protect against LDL oxidation in in vitro assays (Schlotte et al. 1998). Beer appears to be more potent than wine or spirits in this respect, possibly due to the higher purine content of beer (van der Gaag et al. 2000b).

In general, much of the evidence for beneficial antioxidant effects of substances in alcoholic beverages arises from in vitro experiments, and some of these effects appear to be difficult to demonstrate consistently in vivo in long-term intervention studies. However, this factor does not rule out the possibility that they may constitute an important part of the cardio-protective impact of alcohol drinking. Future long-term animal feeding studies which include a more direct in vivo testing of the endothelial function may provide a differential picture of the variety of antioxidant mechanisms.

\section{Effects of alcohol consumption on other regulatory systems}

Alcohol and its metabolites may interfere with several additional regulatory systems that may have consequences for the risk of developing coronary artery disease.

\section{Glucose metabolism}

Variation in glycaemic control (haemoglobin $\mathrm{A}_{\mathrm{tc}}$, a glycated haemoglobin) has recently been found to predict subsequent development of IHD even in non-diabetic individuals (Khaw et al. 2001). This finding indicates that, even in the normal range, insulin sensitivity may be important in the development of CHD. Insulin sensitivity is associated with blood pressure (Abbasi et al. 1999), blood lipid profile (Cigolini et al. 1995) and PAI-1 (Abbasi et al. 1999), all of which appear to be independent risk factors for CHD. Furthermore, insulin resistance may progress into overt diabetes (non-insulin-dependent diabetes mellitus; NIDDM), a disease which is associated with high cardiovascular morbidity and mortality. The acute effect of alcohol on insulin sensitivity may differ from a possible chronic effect of habitual moderate alcohol drinking. In most studies ethanol has been found to impair glucose uptake acutely during an intravenous glucose tolerance test (Avogaro et al. 1987; Shah, 1988; Shelmet et al. 1988). 


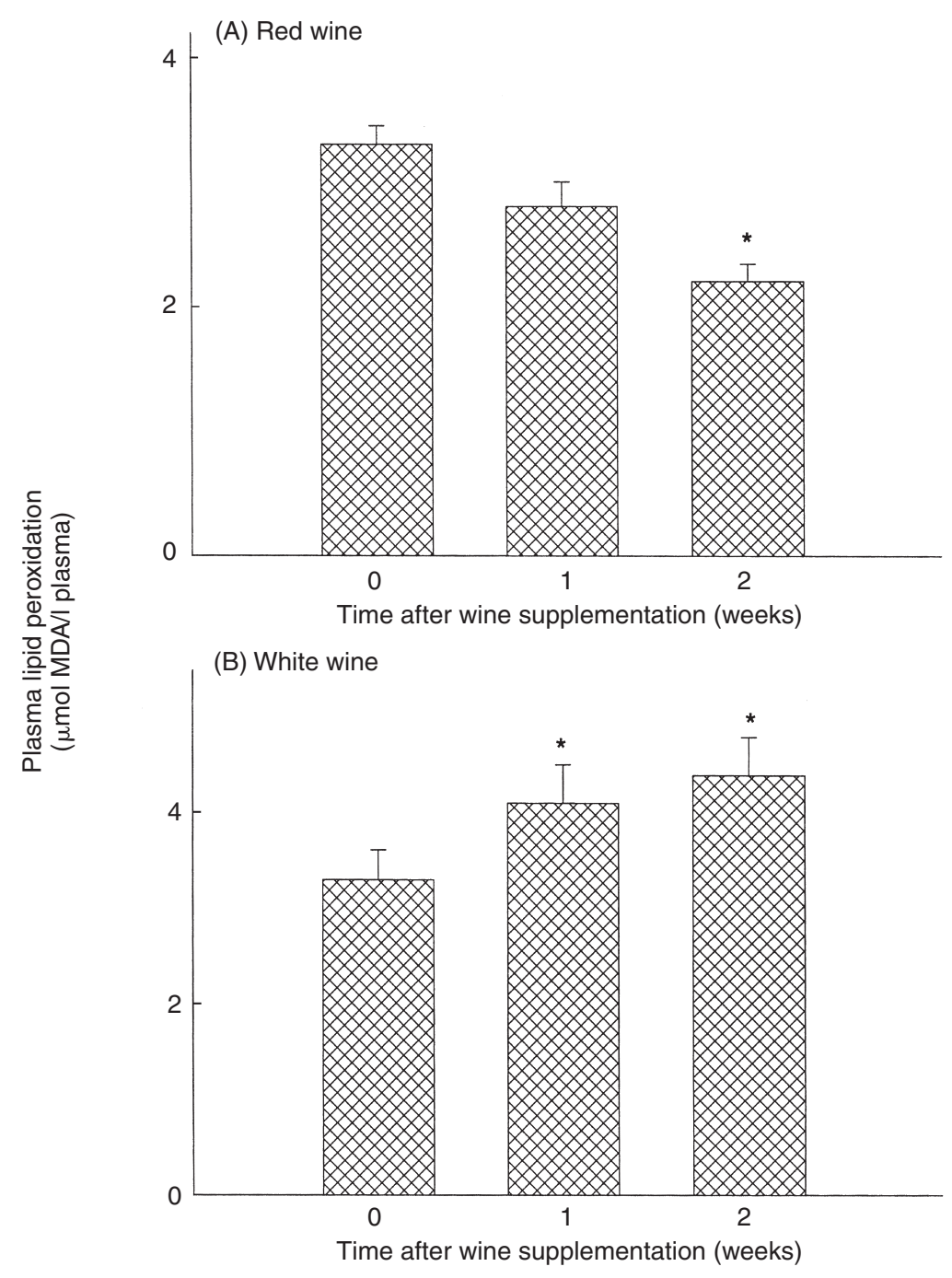

Fig. 6. The effect of 1 and 2 weeks red or white wine consumption on plasma lipid peroxidation after incubation with 2,2'-azobis,2-amidinopropane hydrochloride. MDA, malondialdehyde. Values are means with their standard errors represented by vertical bars for eight and nine samples for red and white wine respectively. ${ }^{*} P<0.05$ v. time 0 . (From Fuhrman et al. 1995; reprinted with permission from the American Society of Clinical Nutrition.)

This effect may be attributable to the hepatic production of acetate, which is oxidised very rapidly (Skutches et al. 1979) and therefore competes with other oxidative substrates in the peripheral tissue. In contrast, several cross-sectional studies have shown decreased fasting insulin levels and improved insulin sensitivity during a glucose challenge in individuals who reported a moderate alcohol intake (Kiechl et al. 1996; Lazarus et al. 1997; Razay \& Heaton, 1997; Flanagan et al. 2000). In one of these studies (Razay \& Heaton, 1997), however, a curvilinear relationship between fasting insulin concentration and alcohol consumption was 
found, as individuals who drank $>40 \mathrm{~g}$ alcohol/d had an increased insulin level compared with moderate consumers. A recent survey also found a similar association (Bell et al. 2000). In this study, however, alcohol consumption was also curvilinearly related to BMI and waist circumference, and the effect of alcohol intake vanished after adjustment for these factors. In addition to the cross-sectional surveys, most large-scale prospective studies indicate that moderate alcohol consumption has a protective effect on the development of NIDDM (Ajani et al. 2000), but one British study (Perry et al. 1995) found a curvilinear trend between alcohol intake and the 13-year follow-up incidence of NIDDM. Experimental data on the long-term impact of alcohol on insulin sensitivity are sparse and do not support the epidemiological findings, as 6 or 10 weeks of moderate wine consumption has been reported to have no effect on fasting insulin levels or sensitivity (Cordain et al. 1997, 2000). The physiological mechanism behind the possible improvement in insulin sensitivity associated with regular moderate alcohol consumption is not obvious, and further experiments with longer intervention periods and a controlled diet should be conducted in order to establish whether the epidemiological observations reflect a true effect of alcohol, or whether they are a result of an unrecognised confounding effect of dietary (e.g. intake of fatty fish) or other lifestyle factors which may correlate with wine intake (Hagstrup Christensen et al. 2001).

\section{Body fat distribution}

The association between abdominal obesity and mortality is well established (Kahn \& Williamson, 1994), and central fat distribution is a strong predictor of death due to CHD (Casassus et al. 1992). However, the extent of visceral fat accumulation may also be of importance for the development of atherosclerosis and CHD in normal-weight subjects (Nakamura et al. 1994; Yamamoto et al. 1997). There is no good evidence from epidemiological or experimental studies that alcohol consumption promotes the development of obesity (Suter et al. 1997), but cross-sectional studies are more consistent in indicating that alcohol intake, even at moderate levels, is associated with abdominal fat distribution (Slattery et al. 1992; Armellini et al. 1993; Cigolini et al. 1996). Abdominal fat distribution in different pathological states is frequently explained by high activity of the hypothalamicpituitary-adrenal axis. Alcoholism has been associated with an increased release of glucocorticoids (Stokes, 1973). There has been speculation therefore, as to whether such a mechanism may also be involved in individuals drinking moderate levels of alcohol. However, plasma cortisol level does not seem to be influenced by moderate drinking (Prinz et al. 1980; Ida et al. 1992; Handa et al. 1994). Nevertheless, central neuroendocrine mechanisms may be involved, as the androgen level has been found to be positively related to alcohol consumption in non-alcoholic women (Cigolini et al. 1996). Furthermore, in these mostly non-obese women alcohol intake was also correlated positively to waist:hip circumference ratio adjusted for BMI, smoking and visceral abdominal fat area. Although alcohol consumption may promote upper body fat accumulation, the pathophysiology relating body fat distribution to CHD risk factors such as hypertension and hyperinsulinaemia has not been sufficiently elucidated to allow the conclusion that social alcohol drinking may exert a detrimental effect in lean individuals by its possible influence on fat deposition. Nevertheless, if alcohol consumption, in the case of obesity, promotes excessive intra-abdominal fat deposition, it could contribute to the development of diabetes and CHD. However, obesity-promoting factors such as social poverty probably act in concert with alcohol drinking to establish the 'beer belly'. 


\section{Blood pressure}

Hypertension is a very strong predictor of CHD and, based on large-scale epidemiological studies, it has been calculated that a general population-based reduction in diastolic blood pressure by as little as $2 \mathrm{mmHg}$ can be anticipated to reduce the incidence of CHD by $6 \%$ in a Western population (Cook et al. 1995). Based on this factor, studies such as that performed by Aguilera et al. (1999) on alcoholics, which demonstrated a $6.6 \mathrm{mmHg}$ reduction in $24 \mathrm{~h}$ ambulatory diastolic blood pressure after 1 month of abstinence, may give cause for some concern. In another study a decline in $24 \mathrm{~h}$ ambulatory systolic blood pressure of between $2 \cdot 2$ and $3.1 \mathrm{mmHg}$ (but not in diastolic blood pressure) was found in men with a customary moderate to heavy alcohol consumption (30-71 ml/d) after 4 weeks during which their intake was reduced by approximately $80 \%$ (Rakic et al. 1998). Studies of shorter duration (4 d), but also with a high level of alcohol manipulation ( $1 \mathrm{~g} / \mathrm{kg}$ body weight per $\mathrm{d})$, did not show a hypertensive effect of alcohol on an average $24 \mathrm{~h}$ basis, but suggested that a greater variation in blood pressure may be related to alcohol consumption (Howes et al. 1990; Maiorano et al. 1995; O'Callaghan et al. 1995). Furthermore, the impact of alcohol on blood pressure may be biphasic, as a depressor effect caused by flushing during intoxification may be followed by a lower depressor effect (Abe et al. 1994) which may, however, be more sustained. The flushing effect may be most obviously marked in Mongolians due to their slower metabolism of acetaldehyde.

Observational studies confirm the experimental findings that heavy drinking may have a hypertensive effect (Arkwright et al. 1982; Cooke et al. 1983; Gillman et al. 1995), but these investigations have produced conflicting results with regard to the effect of light or moderate alcohol consumption on blood pressure. Some of these studies suggest a positive linear relationship with the level of alcohol intake, starting from zero consumption, after accounting for smoking and other confounders (Arkwright et al. 1982; Cooke et al. 1983). A large-scale prospective study found that women drinking 20-34 g alcohol/d had a relative risk of $1.4 \mathrm{com}-$ pared with non-drinkers for having developed hypertension at 4-year follow-up, independent of smoking and dietary variables (Witteman et al. 1990). In contrast, in a smaller study on 352 male employees at an automobile factory who had a daily average alcohol consumption of $22 \mathrm{~g}$ and mainly drank beer, no independent relationships between alcohol intake and systolic or diastolic blood pressure were detected (Simon et al. 1988). Moreover, one study on younger adults has reported a trend towards a curvilinear relationship between alcohol consumption and blood pressure, with those individuals drinking between 2 and 3 units/d having the lowest diastolic blood pressure (Fig. 7; Gillman et al. 1995). Gender has been proposed to influence the relationship between blood pressure and alcohol consumption (van Leer et al. 1994). As blood pressure is very sensitive to different lifestyle factors, the risk that these observational studies may be flawed by unrecognised confounding factors may be substantial. Furthermore, only blood pressure measured at the consultation with the physician, which is susceptible to the anxiety of the subject, was recorded in these investigations. Further studies which introduce prolonged periods with light alcohol consumption and monitor ambulatory blood pressure are therefore required to further elucidate the impact of social drinking on blood pressure.

\section{Effects on the myocardium}

Many individuals are familiar with the arrhythmogenic effect of alcohol, which has been observed in heavy drinkers in acute electrophysiological experiments (Greenspon \& Schaal, 1983). Furthermore, in addition to the direct effect which alcohol exerts on the electrophysio- 

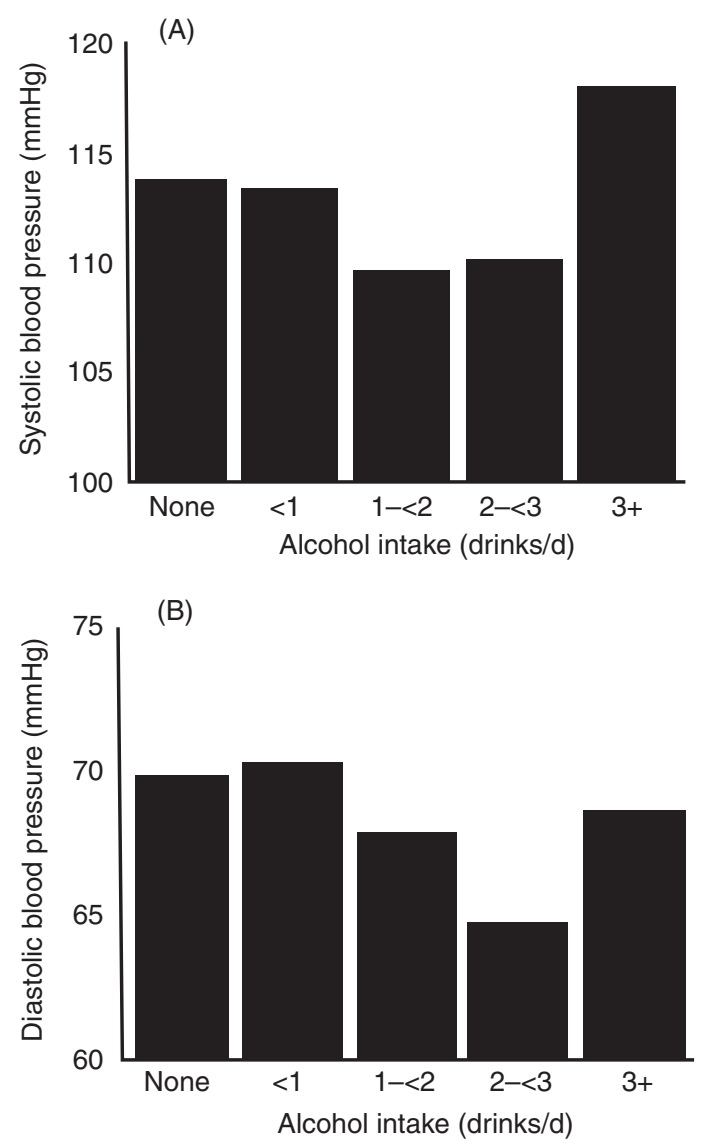

Fig. 7. Mean systolic (A) and diastolic (B) blood pressure for 316 young adults from East Boston, MA, USA, adjusted for age, sex and BMI, grouped according to level of daily alcohol intake. (From Gillman et al. 1995; reprinted with permission from Lippincott Williams \& Wilkins.)

logical properties of the myocardium, moderate doses of alcohol ( $1 \mathrm{~g} / \mathrm{kg}$ body weight $)$ have been reported to result in an acute reduction in the parasympathetic stimulation of the heart in healthy subjects, as reflected by a decline in heart rate variability (Koskinen et al. 1994). Individuals with a low $24 \mathrm{~h}$ heart rate variability have been found to have a substantially higher risk for sudden cardiac death than individuals with a high $24 \mathrm{~h}$ heart rate variability, even after cardiac dysfunctions and history of MI have been accounted for (Algra et al. 1993). Heart rate variability is a strong predictor of arrhythmic events in patients post infarction (Hohnloser et al. 1997). The arrhythmogenic effect of alcohol could therefore potentially reduce the chance of surviving an MI. The presence of this effect of alcohol is supported by prospective observations that the proportion of incidences of cardiac death which could be classified as sudden was greater amongst heavy drinkers (Wannamethee \& Shaper, 1992). Whether the increased risk of sudden cardiac death in alcoholics is due to an acute arrhythmogenic effect or to subclinical structural changes in their myocardium, which may affect its electrophysiological properties, or to a combination of both factors, is not clear. Furthermore, it is not known whether heavy drinking may precipitate non-MI-related fatal arrhythmia in predisposed individuals. 
It is unlikely that the arrhythmogenic effect of alcohol contributes substantially to the overall effect of light drinking on cardiac death, even in terms of surviving an MI. In fact, moderate drinking has been reported to reduce first MI case fatality in a prospective study (Wannamethee et al. 1995). However, in a large-scale prospective study of male physicians (Albert et al. 1999) a nadir for sudden cardiac death was found at five to six drinks weekly with those drinking two or more drinks daily being at higher risk of sudden cardiac death. In contrast, the risk of nonsudden cardiac death and non-fatal MI steadily declined with an alcohol consumption of more than one drink daily. The disparity between the relationships may be attributable to the acute detrimental effect of large amounts of alcohol on fibrinolysis or the electrophysiological stability of the heart. These factors may have a stronger impact on the risk for acute cardiac events than the gradual development of IHD.

\section{Conclusion}

There is substantial epidemiological evidence that a light regular alcohol intake has a preventive effect on CHD. This evidence is supported by a large quantity of experimental data indicating several different factors (lipid metabolism, endothelial function, platelet activity and thrombogenic factors) which may convey the protective effect of alcohol per se. In addition, red wine in particular, but also beer and spirits, may contain substances that enhance the effect of alcohol by an antioxidant effect. However, the relative role that these different factors may play is not well established. Future research will probably reveal new substances and mechanisms which contribute to the cardio-protective effect of alcoholic beverages. It must be emphasised, however, that there is strong observational and experimental evidence that the beneficial cardiovascular effects of alcohol are reversed with heavy or binge drinking. Just one glass of wine or beer daily with the evening meal may be optimal in terms of life expectancy.

\section{Acknowledgements}

We would like to thank The Danish Brewers Association, The Toubro Foundation and The GrethePedersen Foundation for supporting this project. Furthermore, we acknowledge Christina Cuthbertson for the linguistic revision of the manuscript.

\section{References}

Abbasi F, McLaughlin T, Lamendola C, Lipinska I, Tofler G \& Raeven GM (1999) Comparison of plasminogen activator inhibitor-1 concentration in insulin-resistant versus insulin-sensitive healthy women. Arteriosclerosis, Thrombosis and Vascular Biology 19, 2818-2821.

Abe H, Kawano Y, Kojima S, Ashida T, Kuramochi M, Matsuoka H \& Omae T (1994) Biphasic effects of repeated alcohol intake on 24-hour blood pressure in hypertensive patients. Circulation 89, 2626-2633.

Abramson JL, Williams SA, Krumholz HM \& Vaccarino V (2001) Moderate alcohol consumption and risk of heart failure among older persons. Journal of the American Medical Association 285, 1971-1977.

Aguilera MT, de la Sierra A, Coca A, Estruch R, Fernández-Solá J \& Urbano-Márquez A (1999) Effect of alcohol abstinence on blood pressure. Assessment by 24-hour ambulatory blood pressure monitoring. Hypertension 33, 653-657.

Ajani UA, Hennekens CH, Spelsberg A \& Manson JE (2000) Alcohol consumption and risk of type 2 diabetes mellitus among US male physicians. Archives of Internal Medicine 160, 1025-1030.

Albert CM, Manson JE, Cook NR, Ajani UA, Gaziano M \& Hennekens CH (1999) Moderate alcohol consumption and the risk of sudden cardiac death among US male physicians. Circulation 100, 944-950.

Algra A, Tijssen JG, Roelandt JR, Pool J \& Lubsen J (1993) Heart rate variability from 24-hour electrocardiography and the 2-years risk for sudden death. Circulation 88, 180-185. 
Anonymous (1987) Moderate alcohol consumption increases plasma high-density lipoprotein cholesterol. Nutrition Reviews 45, 8-10.

Arkwright PD, Beilen LJ, Rouse I, Armstrong BK \& Vandongen R (1982) Effects of alcohol use and other aspects of lifestyle on blood pressure levels and prevalence of hypertension in a working population. Circulation 66, 60-66.

Armellini F, Zamboni M, Frigo L, Mandragona R, Robbi R, Micciolo R \& Bosello O (1993) Alcohol consumption, smoking habits and body fat distribution in Italian men and women aged 20-60 years. European Journal of Clinical Nutrition 47, 52-60.

Avogaro A, Fontana P, Valerio A, Trevisan R, Riccio A, Del Prato S, Nosadini R, Tiengo A \& Crepaldi G (1987) Alcohol impairs insulin sensitivity in normal subjects. Diabetes Research 5, 23-27.

Baraona E \& Lieber CS (1979) Effects of ethanol on lipid metabolism. Journal of Lipid Research 20, 289-315.

Bell RA, Mayer-Davis E, Martin MA, D’Agostino RB \& Haffner SM (2000) Associations between alcohol consumption and insulin sensitivity and cardiovascular disease risk factors. Diabetes Care 23, 1630-1636.

Berliner JA, Navab M, Fogelman AM, Frank JS, Demer LL, Edwards PA, Watson AD \& Lusis AJ (1995) Atherosclerosis: Basic mechanisms. Oxidation, inflammation, and genetics. Circulation 91, 2488-2496.

Bierenbaum ML, Struck ML, Tomeo AC, Halley J \& Watkins TR (1994) Effect of red and white wine on serum lipids, platelet aggregation, oxidation products and antioxidants. Clinical Research 42, 157A Abstr.

Bobak M, Skodova Z \& Marmot M (2000) Effect of beer drinking on risk of myocardial infarction: population based case-control study. British Medical Journal 320, 1378-1379.

Bourne L, Paganga G, Baxter D, Hughes P \& Rice-Evans C (2000) Absorption of ferulic acid from low-alcohol beer. Free Radical Research 32, 273-280.

Brattstöm L \& Wilcken DEL (2000) Homocysteine and cardiovascular disease: cause or effect? American Journal of Clinical Nutrition 72, 315-323.

Brenn T (1986) The Troms $\emptyset$ heart study: alcoholic beverage and coronary risk factors. Journal of Epidemiology and Community Health 40, 249-256.

Burr ML, Fehily AM, Butland BK, Bolton CH \& Eastham RD (1986) Alcohol and high-density-lipoprotein cholesterol: a randomized controlled trial. British Journal of Nutrition 56, 81-86.

Cao G, Russell RM, Lischner N \& Prior RL (1998) Serum antioxidant capacity is increased by consumption of strawberries, spinach, red wine or vitamin C in elderly women. Journal of Nutrition 128, 2383-2390.

Casassus P, Fontbonne A, Thibult N, Ducimetière P, Richard JL, Claude J-R, Warnet J-M, Rosselin G \& Eschwège E (1992) Upper body fat distribution: A hyperinsulinemia-independent predictor of coronary heart disease mortality. The Paris prospective study. Arteriosclerosis and Thrombosis 12, 1387-1392.

Chan MM-Y, Mattiacci JA, Hwang HS, Shah A \& Fong D (2000) Synergy between ethanol and grape polyphenols, quercetin, and resveratrol, in the inhibition of the inducible nitric oxide synthase pathway. Biochemical Pharmacology 60, 1539-1548.

Chen F, Lu Y, Demers LM, Rojanasakul Y, Shi X, Vallyathan V \& Castranova V (1998) Role of hydroxyl radical in silica-induced NF-кB activation in macrophages. Annals of Clinical and Laboratory Science 28, 1-13.

Cigolini M, Seidell JC, Targher G, Deslypere JP, Éllsinger BM, Charzewska J, Cruz A \& Björntorp P (1995) Fasting serum insulin in relation to components of the metabolic syndrome in European healthy men: The European Fat Distribution Study. Metabolism 44, 35-40.

Cigolini M, Targher G, Andreis IAB, Tonoli M, Filippi F, Muggeo M \& De Sandre G (1996) Moderate alcohol consumption and its relation to visceral fat and plasma androgens in healthy women. International Journal of Obesity and Related Disorders 20, 206-212.

Cleophas TJ (1999) Wine, beer and spirits and the risk of myocardial infarction: a systematic review. Biomedicine and Pharmacotherapy 53, 417-423.

Cleophas TJ, Hornstra N, van Hoogstraten B \& van der Meulen J (2000) Homocysteine, a risk factor for coronary artery disease or not? A meta-analysis. American Journal of Cardiology 86, 1005-1009.

Cook NR, Cohen J, Herbert PR, Taylor JO \& Hennekens CH (1995) Implications of small reductions in diastolic blood pressure for primary prevention. Archives of Internal Medicine 155, 701-709.

Cooke KM, Frost G \& Stokes GS (1983) Blood pressure and its relationship to low levels of alcohol consumption. Clinical and Experimental Pharmacology and Physiology 10, 229-233.

Cordain L, Bryan ED, Melby CL \& Smith MJ (1997) Influence of moderate daily wine consumption on body weight regulation and metabolism in healthy free-living males. Journal of the American College of Nutrition 16, $134-139$.

Cordain L, Melby CL, Hamamoto AE, O Neill DS, Cornier MA, Barakat HA, Israel RG \& Hill JO (2000) Influence of moderate chronic wine consumption on insulin sensitivity and other correlates of syndrome $\mathrm{X}$ in moderately obese women. Metabolism 49, 1473-1478.

Couzigou P, Fleury B, Crockett R, Rautou JJ, Blanchard P, Lemoine F, Richard-Molard B \& Béraud C (1984) High density lipoprotein cholesterol and apoprotein A1 in healthy volunteers during long-term moderate alcohol intake. Annals of Nutrition and Metabolism 28, 377-384.

Crouse JR \& Grundy SM (1984) Effects of alcohol on plasma lipoproteins and cholesterol and triglyceride metabolism in man. Journal of Lipid Research 25, 486-496.

Cuevas AM, Guasch V, Castillo O, Irribarra V, Mizon C, San Martin A, Strobel P, Perez D, Germain AM \& Leighton F (2000) A high-fat diet induces and red wine counteracts endothelial dysfunction in human volunteers. Lipids 35, $143-148$. 
Demrow HS, Slane PR \& Folts JD (1995) Administration of wine and grape juice inhibits in vivo platelet activity and thrombosis in stenosed canine coronary arteries. Circulation 91, 1182-1188.

Diaz MN, Frei B, Vita JA \& Keaney JF (1997) Antioxidants and atherosclerotic heart disease. New England Journal of Medicine 337, 408-416.

Dimmitt SB, Rakic V, Puddey IB, Baker R, Oostryck R, Adams MJ, Chesterman CN, Burke V \& Beilin LJ (1998) The effect of alcohol on coagulation and fibrinolytic factors: a controlled trial. Blood Coagulation and Fibrinolysis 9 , 39-45.

Fenn CG \& Littleton JM (1982) Inhibition of platelet aggregation by ethanol in vitro shows specificity for aggregating agent used and is influenced by platelet lipid composition. Thrombosis and Haemostasis 48, 49-53.

Fitzpatrick DF, Hirschfield SL \& Coffey RG (1993) Endothelium-dependent vasorelaxing activity of wine and other grape products. American Journal of Physiology 265, H774-H778.

Flanagan DEH, Moore VM, Godsland IF, Cockington RA, Robinson JS \& Phillips DI (2000) Alcohol consumption and insulin resistance in young adults. European Journal of Clinical Investigation 30, 297-301.

Flesch M, Schwarz A \& Böhm M (1998) Effects of red and white wine on endothelial-dependent vasorelaxation of rat aorta and human coronary arteries. American Journal of Physiology 275, H1183-H1190.

Frankel EN, Kanner J, German JB, Parks E \& Kinsella JE (1993) Inhibition of oxidation of human low-density lipoprotein by phenolic substances in red wine. Lancet 341, 454-457.

Fuhrman B, Lavy A \& Aviram M (1995) Consumption of red wine with meals reduces the susceptibility of human plasma and low-density lipoprotein to lipid peroxidation. American Journal of Clinical Nutrition 61, 549-554.

Fumeron F, Betoulle D, Luc G, Behague I, Ricard S, Poirier O, Jemaa R, Evans A, Arveiler D, Marques-Vidal P, Bard J-M, Fruchart J-C, Ducimetière P, Apfelbaum M \& Cambien F (1995) Alcohol intake modulates the effect of polymorphism of the cholesteryl ester transfer protein gene on plasma high density lipoprotein and risk of myocardial infarction. Journal of Clinical Investigation 96, 1664-1671.

Gasbarrini A, Addolorato G, Simoncini M, Gasbarrini G, Fantozzi P, Mancini F, Montanari L, Nardini M, Ghiselli A \& Scaccini C (1998) Beer affects oxidative stress due to ethanol in rats. Digestive Diseases and Science 43, $1332-1338$.

Gaziano JM, Buring JE, Breslow JL, Goldhaber SZ, Rosner B, VanDenburgh M, Willet W \& Hennekens CH (1993) Moderate alcohol intake, increased levels of high-density lipoprotein and its subfractions, and decreased risk of myocardial infarction. New England Journal of Medicine 329, 1829-1834.

Gaziano JM, Hennekens CH, Godfried SL, Sesso HD, Glynn RJ, Breslow JL \& Buring JE (1999) Type of alcoholic beverage and risk of myocardial infarction. American Journal of Cardiology 83, 52-57.

Ghiselli A, Nardini M, Baldi A \& Scaccini C (1998). Antioxidant activity of different phenolic fractions separated from an Italian red wine. Journal of Agricultural and Food Chemistry 46, 361-367.

Ghiselli A, Natella F, Guidi A, Montanri L, Fantozzi P \& Scaccini C (2000) Beer increases plasma antioxidant capacity in humans. Journal of Nutritional Biochemistry 11, 76-80.

Gillman MW, Cook NR, Evans DA, Rosner B \& Hennekens CH (1995) Relationship of alcohol intake with blood pressure in young adults. Hypertension 25, 1106-1110.

Gordon T, Ernst N, Fisher M \& Rifkind BM (1981) Alcohol and high-density lipoprotein cholesterol. Circulation 64, Suppl. III, 63-67.

Gorinstein S, Zemser M, Berliner M, Goldstein R, Libman I, Trakhtenberg S \& Caspi A (1997a) Moderate beer consumption and positive biochemical changes in patients with coronary atherosclerosis. Journal of Internal Medicine 242, 219-224.

Gorinstein S, Zemser M, Lichman I, Berebi A, Kleipfish A, Libman I, Trakhtenberg S \& Caspi A (1997b) Moderate beer consumption and the blood coagulation in patients with coronary artery disease. Journal of Internal Medicine 241, 47-51.

Greenspon AJ \& Schaal SF (1983) The holiday heart: electrophysiologic studies of alcohol effects in alcoholics. Annals of Internal Medicine 98, 135-139.

Grønbæk M, Deis A, Sørensen TIA, Becker U, Borch-Johansen K, Müller C, Schnohr P \& Jensen G (1994) Influence of sex, age, body mass index, and smoking on alcohol intake and mortality. British Medical Journal 308, 302-306.

Grønbæk M, Deis A, Sørensen TIA, Becker U, Schnohr P \& Jensen G (1995) Mortality associated with moderate intakes of wine, beer, or spirits. British Medical Journal 310, 1165-1169.

Grundy SM (2001) Non-high-density lipoprotein cholesterol level as potential risk predictor and therapy target. Archives of Internal Medicine 161, 1379-1380.

Gryglewski RJ, Palmer RM \& Moncada S (1986) Superoxide anion is involved in the breakdown of endotheliumderived vascular relaxing factor. Nature 320, 454-456.

Hagiage M, Marti C, Rigaud D, Senault C, Fumeron F, Apfelbaum M \& Girard-Globa A (1992). Effect of moderate alcohol intake on the lipoproteins of normotriglyceridemic obese subject compared with normoponderal controls. Metabolism 41, 856-861.

Hagstrup Christensen J, Skou AS, Fog L, Ellegaard Hansen V, Vesterlund T, Dyerberg J, Toft E \& Berg Schmidt E (2001) Marine $n-3$ fatty acids, wine intake, and heart rate variability in patients referred for coronary angiography. Circulation 103, 651-657.

Handa K, Kono S, Ishii H, Shinchi K, Imanishi K \& Arakawa K (1994) Relationship of alcohol consumption and smoking to plasma cortisol and blood pressure. Journal of Human Hypertension 8, 891-894.

Hartung GH, Foreyt JP, Mitchell RE, Mitchell JG, Reeves RS \& Gotto AM (1983) Effects of alcohol intake on high-density lipoprotein cholesterol levels in runners and inactive men. Journal of the American Medical Association 249, 747-750. 
Hartung GH, Foreyt JP, Reeves RS, Krock LP, Patsch W, Patsch JR \& Gotto AM (1990) Effect of alcohol dose on plasma lipoprotein subfractions and lipolytic enzyme activity in active and inactive men. Metabolism 39, 81-86.

Haskell WL, Camargo C, Williams PT, Vranizan KM, Krauss RM, Lindgren FT \& Wood PD (1984) The effect of cessation and resumption of moderate alcohol intake on serum high-density-lipoprotein subfractions. New England Journal of Medicine 310, 805-810.

Heery JM, Kozak M, Stafforini DM, Jones DA, Zimmerman GA \& McIntyre TM (1995) Oxidatively modified LDL contains phospholipids with platelet-activating factor-like activity and stimulates the growth of smooth muscle cells. Journal of Clinical Investigation 96, 2322-2330.

Hein HO, Suadicani P \& Gyntelberg F (1996) Alcohol consumption, serum low density lipoprotein cholesterol concentration, and risk of ischaemic heart disease: six year follow up in the Copenhagen male study. British Medical Journal 312, 736-741.

Hendriks HF, Veenstra J, Van Tol A, Groener JEM \& Schaafsma G (1998) Moderate doses of alcoholic beverages with dinner and postprandial high density lipoprotein composition. Alcohol and Alcoholism 33, 403-410.

Hendriks HFJ, Veenstra J, Wierik EJMV, Schaafsma G \& Kluft C (1994) Effect of moderate dose of alcohol with evening meal on fibrinolytic factors. British Medical Journal 308, 1003-1006.

Hertog MGL, Feskens EJM, Hollman PCH, Katan MB \& Kromhout D (1993) Dietary antioxidant flavonoids and risk of coronary heart disease: the Zutphen Elderly Study. Lancet 342, 1007-1011.

Hertog MGL, Kromhout D, Aravanis C, Blackburn H, Buzina R, Fidanza F, Giampaoli S, Jansen A, Menotti A, Nedeljkovic S, Pekkarinen M, Simic BS, Toshima H, Feskens EJM, Hollman PCH \& Katan MB (1995) Flavonoid intake and long-term risk of coronary heart disease and cancer in the seven countries study. Archives of Internal Medicine 155, 381-386.

Hillbom M, Muuronen A, Lowbeer C, Anggard E, Bevibng H \& Kangasaho M (1985) Platelet thromboxane formation and bleeding time is influenced by ethanol withdrawal but not by cigarette smoking. Thrombosis and Haemostasis 53, 419-422.

Hines LM, Stampfer MJ, Ma J, Gaziano M, Ridker PM, Hankinson SE, Sacks F, Rimm EB \& Hunter DJ (2001) Genetic variation in alcohol dehydrogenase and the beneficial effect of moderate alcohol consumption on myocardial infarction. New England Journal of Medicine 344, 549-555.

Hohnloser SH, Klingenheben T, Zabel M \& Li YG (1997) Heart rate variability used as an arrhythmia risk stratifier after myocardial infarction. Pacing and Clinical Electrophysiology 20, 2594-2601.

Hokanson JE, Brunzell JD, Jarvik GP, Wijsman EM \& Austin MA (1999) Linkage of low-density lipoprotein size to the lipoprotein lipase gene in heterozygous lipoprotein lipase deficiency. American Journal of Human Genetics 64, 608-618.

Hooper L, Ness AR \& Smith GD (2001) Meta-analysis of effect of high vs low vitamin E intake on cardiovascular mortality for observational and intervention studies. Lancet 357, 1705.

Howes LG, Krum H \& Phillips PA (1990) Effects of regular alcohol consumption on 24 hour ambulatory blood pressure recordings. Clinical and Experimental Pharmacology and Physiology 17, 247-250.

Hulley SB \& Gordon S (1981) Alcohol and high-density lipoprotein cholesterol. Causal inference from diverse study designs. Circulation 64, Suppl. III, 57-63.

Ida Y, Tsujimaru S, Nakamaura K, Shirao I, Mukasa H, Egami H \& Nakazawa Y (1992) Effects of acute and repeated alcohol ingestion on hypothalamic-pituitary-gonadal and hypothalamic-pituitary-adrenal functioning in normal males. Drug and Alcohol Dependence 31, 57-64.

Kahn HS \& Williamson DF (1994) Abdominal obesity and mortality risk among men in nineteenth-century North America. International Journal of Obesity 18, 686-691.

Kakko S, Tamminen M, Pälvänsalo M, Kauma H, Rantala AO, Lilja M, Reunanen A, Kemäniemi YA \& Savolainen MJ (2000) Cholesteryl ester transfer protein gene polymorphisms are associated with carotid atherosclerosis in men. European Journal of Clinical Investigation 30, 18-25.

Kauhanen J, Kaplan GA, Goldberg DE, Salonen R \& Salonen JT (1999) Pattern of alcohol drinking and progression of atherosclerosis. Arteriosclerosis, Thrombosis and Vascular Biology 19, 3001-3006.

Khaw K-T, Wareham N, Luben R, Bingham S, Oakes S \& Welch A (2001) Glycated haemoglobin, diabetes, and mortality in men in Norfolk cohort of European Prospective Investigation of Cancer and Nutrition (EPIC-Norfolk). British Medical Journal 322, 1-6.

Kiechl S, Willeit J, Poewe W, Egger G, Oberhollenzer F, Muggeo M \& Bonora E (1996) Insulin sensitivity and regular alcohol consumption: large, prospective, cross sectional population study (Bruneck study). British Medical Journal 313, 1040-1044.

Kiechl S, Willeit J, Rungger G, Egger G, Oberhollenzer F \& Bonora E (1998) Alcohol consumption and atherosclerosis: what is the relation. Prospective results from the Bruneck Study. Stroke 29, 900-907.

Kim KM, Chun SB, Koo MS, Choi WJ, Kim TW, Kwon YG, Chung HT, Billiar TR \& Kim YM (2001) Differential regulation of NO availability from macrophages and endothelial cells by the garlic component S-allyl cysteine. Free Radical Biology and Medicine 30, 747-756.

Klurfeld DM \& Kritchevsky D (1981) Different effects of alcoholic beverages on experimental atherosclerosis in rabbits. Experimental and Molecular Pathology 34, 62-71.

Koskinen P, Virolainen J \& Kupari M (1994) Acute alcohol intake decreases short-term heart rate variability in healthy subjects. Clinical Science 87, 225-230. 
Langer RD, Criqui MH \& Reed DM (1992) Lipoproteins and blood pressure as biological pathways for effect of moderate alcohol consumption on coronary heart disease. Circulation $\mathbf{8 5}, 910-915$.

LaPorte RE, Cresanta JL \& Kuller LH (1980) The relationship of alcohol consumption to atherosclerotic heart disease. Preventive Medicine 9, 22-40.

Laug WE (1983) Ethyl alcohol enhances plasminogen activator secretion by endothelial cells. Journal of the American Medical Association 250, 772-776.

Lazarus R, Sparrow D \& Weiss ST (1997) Alcohol intake and insulin levels. The Normative Ageing Study. American Journal of Epidemiology 145, 909-916.

Lee AJ, Flanagan PA, Rumley A, Fowkes FGR \& Lowe GDO (1995) Relationship between alcohol intake and tissue plaminogen activator antigen and other haemostatichemostatic factors in the general population. Fibrinolysis 8 , 49-54.

Leo R, Pratico D, Iuliano L, Pulcinelli FM, Ghiselli A, Pignatelli P, Colavita AR, FitzGerald GA \& Violi F (1997) Platelet activation by superoxide anion and hydroxyl radicals intrinsically generated by platelets that had undergone anoxia and then reoxygenated. Circulation 95, 885-891.

Lieber CS (1991) Alcohol, liver, and nutrition. Journal of the American College of Nutrition 10, 602-632.

McConnell MV, Vavouranakis I, Wu LL, Vaughan DE \& Ridker PM (1997) Effects of a single, daily alcoholic beverage on lipid and hemostatic markers of cardiovascular risk. American Journal of Cardiology 80, 1226-1228.

McElduff PM \& Dobson AJ (1997) How much alcohol and how often? Population based case-control study of alcohol consumption and risk of a major coronary event. British Medical Journal 314, 1159-1164.

Maiorano G, Bartolomucci F, Contursi V, Saracino E \& Agostinacchio E (1995) Effect of alcohol consumption versus abstinence on 24-h blood pressure profile in normotensive alcoholic patients. Journal of Hypertension 8, 80-81.

Mantle D \& Preedy VR (1999) Free radicals as mediators of alcohol toxicity. Adverse Drug Reactions and Toxicological Reviews 18, 235-252.

Maresca G, Di Blasio A, Marchioli R \& Di Minno G (1999) Measuring plasma fibrinogen to predict stroke and myocardial infarction. An update. Arteriosclerosis, Thrombosis, and Vascular Biology 19, 1368-1377.

Marmot MG (1984) Alcohol and coronary heart disease. International Journal of Epidemiology 13, 160-167.

Mayer O, Simon J \& Rosolová H (2001) A population study of the influence of beer consumption on folate and homocysteine concentrations. European Journal of Clinical Nutrition 55, 605-609.

Meade TW, Vickers MV, Thompson SG, Stirling Y, Haines AP \& Miller GJ (1985) Epidemiological characteristics of platelet aggregability. British Medical Journal 290, 428-432.

Mennen LI, Balkau B, Vol S, Cacès E \& Eschwège E (1999) Fibrinogen. A possible link between alcohol consumption and cardiovascular disease. Arteriosclerosis, Thrombosis, and Vascular Biology 19, 887-892.

Mezey E (1985) Metabolic effects of alcohol. Federation Proceedings 44, 134-138.

Mikhailidis DP, Barradas MA, Epemolu O \& Dandona P (1987) Ethanol ingestion inhibits human whole blood platelet impedance aggregation. American Journal of Clinical Pathology 88, 342-345.

Miranda CL, Stevens JF, Ivanov V, McCall M, Frei B, Deinzer ML \& Buhler DR (2000) Antioxidant and prooxidant actions of prenylated and nonprenylated chalones and flavones in vitro. Journal of Agricultural and Food Chemistry 48, 3876-3884.

Moro MÁ, Darley-Usmar VM, Goodwin DA, Read NG, Zamora-Pino R, Feelisch M, Radomski MW \& Moncade S (1994) Paradoxical fate and biological actions of peroxynitrite on human platelets. Proceedings of the National Academy of Sciences of the USA 91, 6702-6706.

Nakamura T, Tokunaga K, Shimomura I, Nishida M, Yoshida S, Kotani K, Islam AH, Keno Y, Kobatake T \& Nagai Y (1994) Contribution of visceral fat accumulation to the development of coronary artery disease in non-obese men. Atherosclerosis 107, 239-246.

Nanji AA (1985) Alcohol and ischemic heart disease: wine, beer or both? International Journal of Cardiology 8 , 487-489.

Nappo F, De Rosa N, Marfella R, De Lucia D, Ingrosso D, Perna AF, Farzati B \& Giugliano D (1999) Impairment of endothelial functions by acute hyperhomocysteinemia and reversal by antioxidant vitamins. Journal of the American Medical Association 281, 2113-2118.

Nishiwaki M, Ishikawa T, Ito T, Shige H, Tomiyasu K, Nakajima K, Kondo K, Hashimoto H, Saitoh K \& Manabe M (1994) Effects of alcohol on lipoprotein lipase, hepatic lipase, cholesteryl ester transfer protein, and lecithin:cholesterol acyltransferase in high-density lipoprotein cholesterol elevation. Atherosclerosis 111, 99-109.

Numminen H, Kobayashi M, Uchiyama S, Iwata M, Ikeda Y, Riutta A, Syrjälä M, Kekomaki R \& Hillbom M (2000a) Effects of alcohol and the evening meal on shear-induced platelet aggregation and urinary excretion of protanoids. Alcohol and Alcoholism 35, 594-600.

Numminen H, Syrjälä M, Benthin G, Kaste M \& Hillbom M (2000b) The effect of acute ingestion of a large dose of alcohol on the hemostatic system and its circadian variation. Stroke 31, 1269-1273.

O'Callaghan CJ, Phillips PA, Krum H \& Howes LG (1995) The effects of short-term alcohol intake on clinic and ambulatory blood pressure in normotensive social drinkers. American Journal of Hypertension 8, 572-577.

Pace-Asciak CR, Hahn S, Diamandis EP, Soleas G \& Goldberg DM (1995) The red wine phenolics trans-resveratrol and quercetin block human platelet aggregation and eicosanoid synthesis: Implications for protection against coronary heart disease. Clinica Chimica Acta 235, 207-219.

Pace-Asciak CR, Rounova O, Hahn SE, Diamandis EP \& Goldberg DM (1996) Wines and grape juices as modulators of platelet aggregation in healthy human subjects. Clinica Chimica Acta 246, 163-182. 
Parthasarathy S, Steinberg D \& Witztum JL (1992) The role of oxidized low-density lipoproteins in the pathogenesis of atherosclerosis. Annual Review of Medicine 43, 219-225.

Paunio M, Heinonen O, Virtamo J, Klag MJ, Manninen V, Albanes D \& Comstock GW (1994) HDL cholesterol and mortality in Finnish Men with special reference to alcohol intake. Circulation 90, 2909-2918.

Pellegrini N, Pareti FI, Stabile F, Brusamolino A \& Simonetti P (1996) Effects of moderate consumption of red wine on platelet aggregation and haemostatic variables in healthy volunteers. European Journal of Clinical Nutrition 50, 209-213.

Pendurthi UR, Williams JT \& Rao LVM (1999) Resveratrol, a polyphenolic compound found in wine, inhibits tissue factor expression in vascular cells. A possible mechanism for the cardiovascular benefits associated with moderate consumption of wine. Arteriosclerosis, Thrombosis and Vascular Biology 19, 419-426.

Perry IJ, Wannamethee SG, Walker MK, Thomson AG, Whincup PH \& Shaper AG (1995) Protective study of risk factors for development of non-insulin dependent diabetes in middle aged British men. British Medical Journal 310, 560-564.

Pikaar NA, Wedel M, van der Beek EJ, van Dokkum Wim, Kempen HJM, Kluft C, Ockhuizen T \& Hermus RJJ (1987) Effects of moderate alcohol consumption on platelet aggregation, fibrinolysis, and blood lipids. Metabolism 36, 538-543.

Prentice AM (1995) Alcohol and obesity. International Journal of Obesity and Related Disorders 19, Suppl. 5, S44-S50.

Prinz PN, Roehrs TA, Vitaliano PP, Linnoila M \& Weitzman ED (1980) Effect of alcohol on sleep and night time growth hormone and cortisol concentrations. Journal of Clinical Endocrinology and Metabolism 51, 759-764.

Rakic V, Puddey IB, Burke V, Dimmitt SB \& Beilin LJ (1998) Influence of pattern of alcohol intake on blood pressure in regular drinkers: a controlled trial. Journal of Hypertension 16, 165-174.

Rand ML, Packham MA, Kinlough-Rathbone RL \& Fraser MJ (1988) Effects of ethanol on pathways of platelet aggregation in vitro. Thrombosis and Haemostasis 59, 383-387.

Rao MN, Lin QH, Marmillot P, Seeff LB, Strader DB \& Lakshman MR (2000) High-density lipoproteins from human alcoholics exhibit impaired reverse cholesterol transport function. Metabolism 49, 1406-1410.

Razay G \& Heaton KW (1997) Moderate alcohol consumption has been shown previously to improve insulin sensitivity in men. British Medical Journal 314, 442-443.

Razzaghi H, Aston CE, Hamman RF \& Kamboh MI (2000) Genetic screening of the lipoprotein lipase gene for mutations associated with high triglyceride/low HDL-cholesterol levels. Human Genetics 107, 257-267.

Renaud S \& De Lorgeril M (1992) Wine, alcohol, platelets, and the French paradox for coronary heart disease. Lancet 339, $1523-1526$

Renaud SC, Beswick AD, Fehily AM, Sharp DS \& Elwood PC (1992) Alcohol and platelet aggregation: the Caerphilly prospective heart disease study. American Journal of Clinical Nutrition 55, 1012-1017.

Ridker PM, Vaughan DE, Stampfer MJ, Glynn RJ \& Hennekens CH (1994) Association of moderate alcohol consumption and plasma concentration of endogenous tissue-type plasminogen activator. Journal of the American Medical Association 272, 929-933.

Rimm EB, Giovannucci EL, Willet WC, Colditz GA, Ascherio A, Rosner B \& Stampfer MJ (1991) Prospective study of alcohol consumption and risk of coronary disease in men. Lancet 338, 464-468.

Rimm EB, Klatsky A, Grobbee D \& Stampfer MJ (1996) Review of moderate alcohol consumption and reduced risk of coronary heart disease: is the effect due to beer, wine, or spirits? British Medical Journal 312, 731-736.

Rimm EB, Willett WC, Hu FB, Sampson L, Colditz GA, Manson JE, Hennekens C \& Stampfer MJ (1998) Folate and vitamin $\mathrm{B}_{6}$ from diet and supplements in relation to risk of coronary heart disease among women. Journal of the American Medical Association 279, 359-364.

Rimm EB, Williams P, Fosher K, Criqui M \& Stampfer MJ (1999) Moderate alcohol intake and lower risk of coronary heart disease: meta-analysis of effects on lipids and haemostatic factors. British Medical Journal 319, 1523-1528.

Rubin R (1989) Ethanol interferes with collagen-induced platelet activation by inhibition of arachidonic acid mobilization. Archives of Biochemistry and Biophysics 270, 99-113.

Ruf J-C, Berger J-L \& Renaud S (1995). Platelet rebound effect of alcohol withdrawal and wine drinking in rats. Relation to tannins and lipid peroxidation. Arteriosclerosis, Thrombosis and Vascular Biology 15, 140-144.

Rumpler WV, Clevidence BA, Muesing RA \& Rhodes DG (1999) Change in women's plasma lipid and lipoprotein concentrations due to moderate consumption of alcohol are affected by dietary fat level. Journal of Nutrition 129, 1713-1717.

Savolainen MJ, Hannuksela M, Seppänen S, Kervinen K \& Kesäniemi YA (1990) Increased high-density lipoprotein cholesterol concentration in alcoholics is related to low cholesteryl ester transfer protein activity. European Journal of Clinical Investigation 20, 593-599.

Savolainen MJ \& Kesäniemi YA (1995) Effects of alcohol on lipoproteins in relation to coronary heart disease. Current Opinion in Lipidology 6, 243-250.

Schlotte V, Sevanian A, Hochstein P \& Weitmann KU (1998) Effect of uric acid and chemical analogues on oxidation of human low density lipoprotein. Free Radicals in Biology and Medicine 25, 839-847.

Serafini M, Maiani G \& Ferro-Luzzi A (1998) Alcohol-free red wine enhances plasma antioxidant capacity in humans. Journal of Nutrition 128, 1003-1007.

Serebruany VL, Lowry DR, Fuzailov SY, Levine DJ, O’Connor CM \& Gurbel PA (2000) Moderate alcohol consumption is associated with decreased platelet activity in patients presenting with acute myocardial infarction. Journal of Thrombosis and Thrombolysis 9, 229-234. 
Shah JH (1988) Alcohol decreases insulin sensitivity in healthy subjects. Alcohol and Alcoholism 23, $103-109$.

Shelmet JJ, Reichard GA, Skutches CL, Hoeldtke RD, Owen OE \& Boden G (1988) Ethanol causes acute inhibition of carbohydrate, fat, and protein oxidation and insulin resistance. Journal of Clinical Investigation 81, 1137-1145.

Sillanaukee P, Koivula T, Jokela H, Myllyharju H \& Seppä K (1993) Relationship of alcohol consumption to changes in HDL-subfractions. European Journal of Clinical Investigation 23, 486-491.

Sillanaukee P, Koivula T, Jokela H, Pitkäjärvi T \& Seppä K (2000) Alcohol consumption and its relation to lipid-based cardiovascular risk factors among middle-aged women: the role of $\mathrm{HDL}_{3}$ cholesterol. Atherosclerosis 152, 503-510.

Simon J, Filipovsky J, Rosolová H, Topolcan O \& Karlicek V (1988) Cross-sectional study of beer consumption and blood pressure in middle-aged men. Journal of Human Hypertension 2, 1-6.

Skutches CL, Holroyde CP, Myers RN, Paul P \& Reichard GA (1979) Plasma acetate turnover and oxidation. Journal of Clinical Investigation 64, 708-713.

Slattery ML, McDonald A, Bild DE, Caan BJ, Hilner JE, Jacobs DR \& Liu K (1992) Associations of body fat and its distribution with dietary intake, physical activity, alcohol, and smoking in blacks and whites. American Journal of Clinical Nutrition 55, 943-949.

Stampfer MJ, Sacks FM, Simonettea S, Willett WC \& Hennekens CH (1991) A prospective study of cholesterol, apolipoproteins, and the risk of myocardial infarction. New England Journal of Medicine 325, 373-381.

Stokes PE (1973) Adrenocortical activation in alcoholics during chronic drinking. Annals of the New York Academy of Sciences 215, 77-83.

Stubbs CD \& Rubin R (1992) Effect of ethanol on platelet phopholipase A2. Lipids 27, 255-260.

Suter PM, Häsler E \& Vetter W (1997) Effects of alcohol on energy metabolism and body weight regulation: Is alcohol a risk factor for obesity? Nutrition Reviews 55, 157-171.

Taylor KG, Carter TJ, Valente AJ, Wright AD, Smith JH \& Matthews KA (1981) Sex differences in the relationships between obesity, alcohol consumption and cigarette smoking and serum lipid and lipoprotein concentrations in a normal population. Atherosclerosis 38, 11-18.

Thögersen AM, Jansson J-H, Boman K, Nilsson TK, Weinehall L, Huhtasaari F \& Hallmans G (1998) High plasminogen activator inhibitor and tissue plasminogen activator levels in plasma precede a first acute myocardial infarction in both men and women. Evidence for the fibrinolytic system as an independent primary risk factor. Circulation 98, 2241-2247.

Thome J, Foley P, Gsell W, Davids E, Wodarz N, Wiesbeck A, Böning J \& Riederer P (1997) Increased concentrations of manganese superoxide dismutase in serum of alcohol-dependent patients. Alcohol and Alcoholism 32, 65-69.

Tjønneland A, Grønbæk M, Stripp C \& Overvad K (1999) Wine intake and diet in a random sample of 48763 Danish men and women. American Journal of Clinical Nutrition 69, 49-54.

Trevithick CC, Vinson JA, Caulfield J, Rahman F, Derksen T, Bocksch L, Hong S, Srefan A, Teufel K, Wu N, Hirst M \& Trevithick JR (1999) Is ethanol an important antioxidant in alcoholic beverages associated with risk reduction of cataract and atherosclerosis? Redox Report 4, 89-93.

van de Wiel A, van Golde PM, Kraaijenhagen RJ, von dem Borne PAK, Bouma BN \& Hart HC (2001) Acute inhibitory effect of alcohol on fibrinolysis. European Journal of Clinical Investigation 31, 164-170.

van der Gaag MS, Ubbink JB, Sillanaukee P, Nikkari S \& Hendriks HFJ (2000a) Effect of consumption of red wine, spirits, and beer on serum homocysteine. Lancet 355, 1522.

van der Gaag MS, van den Berg R, van den Berg H, Schaafsma G \& Hendriks HFJ (2000b) Moderate consumption of beer, red wine and spirits has counteracting effects on plasma antioxidants in middle-aged men. European Journal of Clinical Nutrition 54, 586-591.

van Golde PHM, Sloots LM, Vermeulen WP, Wielders JPM, Hart HC, Bouma BN \& van de Wiel A (1999) The role of alcohol in the anti low density lipoprotein oxidation activity of red wine. Atherosclerosis 147, 365-370.

van Leer EM, Seidell JC \& Kromhout D (1994) Differences in the association between alcohol consumption and blood pressure by age, gender, and smoking. Epidemiology 5, 576-582.

Van Tol A, Groener JE, Scheek LM, Van Gent T, Veenstra J, Van de Pol H, Hendriks HF \& Schaafsma G (1995) Induction of net mass lipid transfer reactions in plasma by wine consumption with dinner. European Journal of Clinical Investigation 25, 390-395.

Veenstra J, Kluft C, Ockhuizen TH, Pol H, Wedel M \& Schaafsma G (1990a) Effects of moderate alcohol consumption on platelet function, tissue-type and plasminogen activator inhibitor. Thrombosis and Haemostasis 63, 345-348.

Veenstra J, Ockhuizen T, van de Pol H, Wedel M \& Schaafsma G (1990b) Effects of a moderate dose of alcohol on blood lipids and lipoproteins postprandially and in the fasting state. Alcohol and Alcoholism 25, 371-377.

Venkov CD, Myers PR, Tanner MA, Su M \& Vaughan DE (1999) Ethanol increases endothelial nitric oxide production through modulation of nitric oxide synthase expression. Thrombosis and Haemostasis 81, 638-642.

Vermeulen EGJ, Stehouwer CDA, Twisk JWR, van den Berg M, de Jong SC, Mackaay AJC, van Campen CMC, Visser FC, Jakobs CAJM, Bulterijs EJ \& Rauwerda JA (2000) Effect of homocysteine-lowering treatment with folic acid plus vitamin $\mathrm{B}_{6}$ on progression of subclinical atherosclerosis: a randomised, placebo-controlled trial. Lancet 355, 517-522.

Vinson JA, Jang J, Yang J, Dabbagh Y, Liang X, Serry M, Proch J \& Cai S (1999) Vitamins and especially flavonoids in common beverages are powerful in vitro antioxidants which enrich lower density lipoproteins and increase their oxidative resistance after ex vivo spiking in human plasma. Journal of Agricultural and Food Chemistry 47, 2502-2504. 
Wannamethee G \& Shaper AG (1992) Alcohol and sudden cardiac death. British Heart Journal 68, $443-448$.

Wannamethee SG \& Shaper AG (1999) Type of alcoholic drink and risk of major coronary heart disease events and allcause mortality. American Journal of Public Health 89, 685-690.

Wannamethee G, Whincup PH, Shaper AG, Walker M \& MacFarlane PW (1995) Factors determining case fatality in myocardial infarction. Who dies in a heart attack? British Heart Journal 74, 324-331.

Whitehead TP, Robinson D, Allaway S, Syms J \& Hale A (1995) Effect of red wine ingestion on the antioxidant capacity of serum. Clinical Chemistry 41, 32-35.

Witteman JC, Willet WC, Stampfer MJ, Colditz GA, Kok FJ, Sacks FM, Speizer FE, Rosner B \& Hennekens CH (1990) Relation of moderate alcohol consumption and risk of systemic hypertension in women. American Journal of Cardiology 65, 633-637.

Witztum JL \& Hörkkö S (1997) The role of oxidized LDL in atherogenesis: Immunological response and anti-phospholipid antibodies. Annals of the New York Academy of Sciences 811, 88-96.

Woo KS, Chook P, Lolin YI, Cheung ASP, Chan RN, Sun YY, Sanderson JE, Metreweli C \& Celermajer DS (1997) Hyperhomocyst(e)inemia is a risk factor for arterial endothelial dysfunction in humans. Circulation 96, 2542-2544.

Xia J, Allenbrand B \& Sun GY (1998) Dietary supplementation of grape polyphenols and chronic ethanol administration on LDL oxidation and platelet function in rats. Life Science 63, 383-390.

Yamamoto M, Egusa G, Hara H \& Yamakido M (1997) Association of intraabdominal fat and carotid atherosclerosis in non-obese middle-aged men with normal glucose tolerance. International Journal of Obesity and Related Disorders 21, 948-951.

Zhang QH, Das K, Siddiqui S \& Myers AK (2000) Effects of acute, moderate ethanol consumption on human platelet aggregation in platelet-rich plasma and whole blood. Alcoholism, Clinical and Experimental Research 24, 528-534. 


\section{Public \\ Health \\ Nutrition}

AN INTERNATIONAL

RESEARCH JOURNAL

PUBLISHED BY

CABI PUBLISHING ON

BEHALF OF THE NUTRITION SOCIETY

To order your subscription or for more information contact:

\section{CABI Publishing,}

$C A B$ International,

Wallingford,

Oxon, OX10 8DE, UK

Tel: +44 (0)1491832111

Fax: +44 (0)1491 829292

Email: publishing@cabi.org

\section{CABI Publishing,}

$C A B$ International,

10 East 40th Street,

Suite 3203,

New York, NY 10016,

USA

Tel: 2124817018

Toll free: 8005284841

Fax: 2126867993

Email: cabi-nao@cabi.org

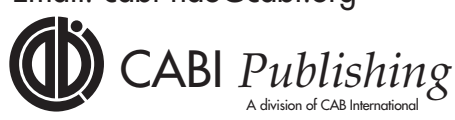

Publishes Public Health Nutrition on behalf of The Nutrition Society

\section{Available on the Internet at}

www.cabi-publishing.org/journals

\section{Journal Editors}

Dr Barrie Margetts (Editor-in-Chief)

Institute of Human Nutrition

University of Southampton, UK

Dr Lenore Arab

(Editor, North America)

Schools of Public Health and Medicine,

University of North Carolina at Chapel Hill, USA

- Essential reading for everyone involved in public health nutrition, practitioners and researchers

- The source for an evidence based approach to the solution of nutrition related health problems

- Recently described by an eminent international scientist as essential reading for all people working in this field

Print only
$£ 275.00$
$\$ 480.00$ Americas only
$\quad 435.00$ EU only

$\begin{array}{cl}\text { Internet only } & \begin{array}{l}\text { Print/Internet } \\ \text { Package }\end{array} \\ £ 265.00 & £ 285.00 \\ \$ 465.00 \text { Americas only } & \begin{array}{l}\$ 500.00 \text { Americas only } \\ 455.00 \text { EU only }\end{array} \\ 420.00 \text { EU only } & 45\end{array}$

A special subscription rate is available for members of The Nutrition Society

Print only, Internet only and Internet/Print Package price

$\$ 85.00$ North and South America

$£ 52.00$ Rest of the World

80.00 Europe

\section{Volume 5 in 6 issues}

We also publish special issues that cover proceedings of meetings or other special reports (all included at no extra cost).

Electronic and paper copies available.

If you have research findings of interest to a wide Public Health Nutrition audience send us your work. For details on layout consult any issue of the journal or visit our web site.

For more information about The Nutrition Society visit www.nutsoc.org.uk 